\title{
CONSTRUCCIÓN DE UNA IDENTIDAD PARTICIPATIVA: SOCIALIZACIÓN EN EL PRIMER AÑO DE ESTUDIOS UNIVERSITARIOS
}

\section{Partaking identity building: socialization in the freshman year college}

José Luis Suárez Domínguez¹, Roberto Anaya Rodríguez

Fecha de recepción: 9 de marzo de 2016

Fecha de aceptación: 19 de mayo de 2016

1- Nacionalidad: Mexicana. Grado: Doctorado en Sociología. Especialización: Actores sociales universitarios, sociología de la educación superior. Adscripción: Universidad Veracruzana. Correo: joseinvest279@gmail.com 2- Nacionalidad: Mexicana. Grado: Doctor en Ciencias Sociales por la UACJ. Especialización: Educación para la democracia, formación de ciudadanía, política educativa, democracia, psicología política, intervención comunitaria, gobierno y política pública. Adscripción: Universidad Veracruzana. Correo: roberto_anaya7@hotmail.com 


\section{Resumen}

Este artículo explora la forma en cómo los estudiantes universitarios construyen una identidad de participación política mediante la socialización que ellos despliegan en el primer año de estudios dentro del área de humanidades en la Universidad Veracruzana. Esta socialización se condensa en la integración de diversos grupos que van complejizándose y cambiando su forma a lo largo del tiempo. Los grupos se articulan, a su vez, mediante un conjunto de prácticas que combinan tiempos, interacciones especificas y orientaciones diversas, generando con ello un sentido de pertenencia a la escuela al definirla bajo ciertos esquemas de legitimidad y reconocerla como un espacio válido desde el cual es posible formar parte de diversas actividades de protesta social.

Palabras clave: Participación política, estudiantes, universidad, grupos de pertenencia.

\section{Abstract}

This paper explores how the college students building a political partaking identity, through their socialization during first year studies in the liberal arts area of Veracruzana State University. This socialization is condensed in the integration of different groups, which become complex and changes its shape over time. Those groups are linked through set of practice, which combine times, specific interactions and different orientations, generating a membership of school sense, when the students define it under legitimacy schemes and recognize it as a valid space from which they may join different social protest activities

Key words: Political participation, students, college, membership groups. 


\section{Introducción}

$\mathrm{E}$ n los últimos cinco años, el estado de Veracruz ha sido el escenario de visibles transformaciones en los ámbitos social, cultural y político, lo cual se refleja en "el modo de proceder" de la estructura institucional de esta entidad federativa tanto como en la dinámica de su acción social.

La irrupción de nuevas fuerzas económicas representadas por diversas empresas que han identificado a la entidad como un territorio de riquezas naturales es una de las principales causas de tales transformaciones. Después de la privatización del sector energético, la que se refiere a los mantos acuíferos ha despertado un interés depredador de empresas como Odebrecht y Aguas de Barcelona. Parece cuestión de tiempo que los muy avanzados acuerdos entre estas empresas y el gobierno del estado se vuelvan oficiales para la concreción de este proyecto.

En el ámbito político, no muy lejos de la dinámica privatizadora, la entidad veracruzana vive otros fenómenos tales como la aprobación de una mini gubernatura de dos años, so pretexto de poner en correspondencia las elecciones presidenciales con las estatales. Esta aprobación fue resultado de una serie de negociaciones entre las dos fuerzas partidistas de mayor presencia en el congreso del estado, con el consecuente desgaste del discurso político, carente de toda legitimidad.

No pueden quedarse al margen del relato los cambios experimentados por algunas de las principales ciudades. Tal es el caso de la capital veracruzana, Xalapa, que en ese mismo lapso ha mostrado un crecimiento poblacional de más de treinta mil personas al pasar de 461, 898 a medio millón de habitantes (Inegi, 2014). El crecimiento poblacional devino en una reestructuración urbana, bajo esa racionalidad de crecimiento tan peculiar en nuestro país: la construcción de plazas comerciales y la devastación de buena parte de los pulmones naturales que nutren a la ciudad gracias a las hectáreas de bosque de niebla y bosque mesófilo.

Estos temas se suman a los que ya están en curso, tales como la excesiva concentración de la estructura burocrática y de servicios en Xalapa, con los problemas que trae consigo el hecho de contar con la mayoría de las carteras gubernamentales en esta ciudad: manifestaciones, protestas casi a diario frente al palacio del gobierno del estado, entre otras cuestiones.

Ante el escenario descrito, algunas instituciones en la entidad han sido sensibles a los cambios sociales y políticos. Las organizaciones no se han quedado atrás, las acciones de protesta e inconformidad se han diversificado e incrementado. El grado de reacción por parte de activistas y defensores sociales, obreros de ingenios cercanos, los 400 pueblos, los pensionados, los sindicatos magisteriales y de servicios, los periodistas, los estudiantes universitarios, entre otros muchos, ilustran muy bien esa dinámica. Complementan la lista la posesión de uno de los últimos lugares en educación básica, el último lugar en desarrollo social y el hecho de ser una de las entidades más inestables en el tema de la seguridad, sin ocuparnos del eco producido por otros fenómenos en el país.

La protesta social varía según los grupos en cuestión, pues entre ellos hay diferencias importantes en el nivel de capital social, político y cultural que detentan. Las reacciones de parte del gobierno del estado son distintas también, en algunos escenarios la negociación y los acuerdos (casi siempre frágiles) se muestran como la solución temporal a las demandas específicas, mientras que en otros el uso de la fuerza y la represión configuran una fórmula recurrente. 
La diversidad de las protestas sociales se convierte en un objeto de investigación, en buena medida porque involucra a conjuntos específicos de actores sociales (los sujetos objeto de la investigación), tanto como a las instituciones con referencia a las cuales ellos toman una posición. La disciplina sociológica se ha encargado, a lo largo de su historia, de las interacciones complejas que produce la acción social frente a las estructuras sociales.

Como se recordará, buena parte de la definición de la sociología clásica descansó en el papel que jugaban las estructuras como entes regulatorios del comportamiento individual y social. En la medida en que esta disciplina evolucionó, al papel de las estructuras se antepuso el problema de la acción social, dando lugar a otros enfoques teóricos, otorgando a los actores libre acción, lejos de constreñimientos estructurales tal y como lo promovían algunas perspectivas en la teoría clásica.

Un hito en la sociología se manifiesta con la aparición de una diversidad de autores (Bourdieu y Wacquant, 1995; Habermas, 1999; Giddens, 2003) quienes mostraron que tanto la acción como la estructura forman parte de los planos explicativos del comportamiento social. Aun cuando la sociología posmoderna ubica en el plano de la acción social uno de los principales referentes para explicar el comportamiento de los actores sociales en las sociedades actuales (Lipovetski, 1983; Bauman, 2013; Touraine, 2013), es importante concebir que las estructuras son cambiantes en el tiempo y han evolucionado tanto como las diversas expresiones de la acción social.

Si la protesta social, entonces, puede construirse analíticamente como un objeto de estudio, de ella derivan algunos problemas de investigación que vale la pena formular. En principio, es pertinente plantear quiénes son los grupos que realizan las demandas sociales, cuál es la naturaleza de las mismas, cuál es el nivel de participación de sus actores, cómo se articulan éstos con el discurso de la protesta y cómo se definen según la legitimidad que poseen.

En este contexto, llama nuestra atención el grupo que constituyen los estudiantes universitarios, en parte por la cercanía de este tipo de actores con nuestra tarea académica, así como por su definición como grupo social altamente legítimo. Ellos han jugado un papel importante en las demandas sociales. La Universidad Veracruzana, en su calidad de entidad más importante en el régimen público de educación superior en el estado, ha sido uno de los principales reductos donde se gestan diversas acciones de inconformidad social.

El hecho de que la Universidad Veracruzana represente un espacio de expresión del malestar social en el estado, desempolva viejos antagonismos de esta institución con el gobierno veracruzano. El tenor ideológico de dichos antagonismos es distinto al de otras décadas, pero equiparable en fuerza e intensidad.

No puede afirmarse que todos los actores estudiantiles y universitarios se involucran de la misma forma y con el mismo grado de conocimiento acerca de la vida social y política. En ese sentido, los estudiantes del área de humanidades han tenido una participación activa y se han convertido en uno de los principales núcleos antagónicos ante las decisiones de la gastada esfera política y de sus notables.

No hay novedad en ello. Profesores y estudiantes de humanidades han estado presentes en otros momentos de lucha social. Puede recordarse la defensa de los derechos de los trabajadores manuales y académicos al inicio de la década de los setenta. Los actores universitarios representantes del área humanística fueron pieza clave como grupos que lograron el reconocimiento de las autoridades gubernamentales a diversas garantías como la salud y los salarios a través de los contratos colectivos de trabajo. El área de Humanidades fue, asimismo, un referente importante en el movimiento estudiantil de 1968 con las correspondientes persecuciones y hostigamientos. Otras épocas, las mismas luchas. 
El área de humanidades es el espacio de socialización que nos interesa definir como el foco de atención y análisis en este artículo. A lo largo de su historia, fue adquiriendo una alta legitimidad y simbólicamente representa un frente en la lucha social en el estado. Es común que se observen algunos cambios en la constitución de los estudiantes como actores sociales y políticos cuando ellos ingresan a alguna de las carreras humanísticas. Este es el argumento central de nuestro estudio.

\section{La socialización en el primer año de estudios universitarios: la conversión de una identidad estudiantil en humanidades}

Al ingresar a la comunidad universitaria, los estudiantes se constituyen como actores sociales cada vez más complejos en cuanto a su socialización se refiere. Este fenómeno puede plantearse como el resultado de entrar en contacto con otros actores. Los estudiantes reconocen los espacios universitarios como los escenarios desde los cuales se vuelve posible participar en la vida social y política y, a partir de esto, construyen una identidad estudiantil. Son portadores -más o menos conscientes- de una alta legitimidad social y desde ahí actúan.

De acuerdo con lo anterior, surgen dos puntos relevantes, entre los cuales se aprecia cierta conexión. El primero se refiere a la manera en que los estudiantes se apropian de los espacios universitarios, desde los cuales son capaces de formular diversas demandas sociales. El segundo se refiere a los patrones de socialización que están presentes en esas formas específicas de apropiarse de los espacios universitarios.

A manera de hipótesis, se propone que en el primer año de los estudios universitarios, los estudiantes son actores con una alta capacidad receptiva, por lo tanto, reciben una influencia en su interacción con otros actores y mediante esa socialización se produce una regulación de su comportamiento social y político. El primer año de estudios universitarios no se concibe únicamente como aquello que ocurre en el espacio escolar, sino que trasciende sus límites; de esta forma, en este periodo, los estudiantes son capaces de desplegar un conjunto de prácticas que los identifica con el rol institucional, ellos construyen un sentido de pertenencia, una ideología estudiantil, reconocen en la institución los propósitos que ésta persigue y los definen como válidos. En esto juegan un papel fundamental las redes sociales digitales, porque permiten que la socialización vaya más allá de los espacios presenciales, permanece el contacto entre estudiantes e incluso se logra cierta articulación con los discursos de otras agrupaciones de lucha social. Con base en esto, proponemos que la actividad social y política de los estudiantes está fuertemente asociada a la actividad que ellos mantienen en el primer año de estudios tanto en el espacio social presencial como en el virtual. El comportamiento estudiantil se expone, a su vez, ante la presencia histórica de ciertos espacios simbólicos construidos a lo largo de varias décadas y que, en el caso del área humanística, están cargados de una alta legitimidad.

Las redes sociales, se convirtieron en la nueva forma de comunicación, acaso en la nueva configuración de una lógica de consumo que ha traído como consecuencia el traslado de la vida privada a la vida pública (Bauman, 2013), pero que indudablemente ha tenido diversos efectos en la manera de concebir la vida social y de participar en ella. La participación social, la formulación de las nuevas demandas de parte de los actores sociales estudiantiles y la conformación de las redes de protesta social, han estado en cierta medida reguladas por la inversión de tiempo que este tipo de actores ha empleado, y que es de 
alguna forma una nueva estructura que dirige la comunicación y socialización, generando así la participación social y política.

La participación en las redes sociales digitales está complementada por el hecho de que las instituciones de educación superior se convirtieron en los espacios más legítimos para articular las nuevas demandas. Desde la perspectiva de Touraine, los actores sociales asumen a las instituciones, hacen uso de ellas y las convierten en sus espacios de participación de la vida política (Touraine, 2013).

\section{Características del estudio emprendido}

Los resultados mostrados en este artículo, proceden de un estudio de tipo longitudinal, emprendido con el fin de explorar diversas categorías y dimensiones de análisis para acercarse a las dinámicas de socialización que tienen lugar en el primer año de estudios universitarios entre los estudiantes de humanidades de la Universidad Veracruzana. En este artículo, se presenta parte de la información recuperada a partir de dos medios básicos de aproximación empírica, la encuesta ${ }^{3}$ y la entrevista. ${ }^{4}$

Se eligió la generación 2011 de reciente ingreso a la universidad, pues debido a las características del estudio longitudinal, resultaba más práctico hacer un seguimiento del primer año sin que el proyecto se prolongara más allá de la programación inicial. A esta generación se le aplicó una encuesta para conocer cómo era el perfil de socialización con el que ellos ingresaron a la institución. Un año después, se hizo una nueva aplicación de la encuesta con la finalidad de conocer los cambios producidos por el hecho de haber cursado ese periodo en la institución. Se intentó hacer un censo, en vez de un muestreo, con la finalidad de captar el mayor número de casos posible, toda vez que algunas carreras en humanidades tienen una población muy reducida y el muestreo nos hubiera dado "poco margen" para el análisis de la información.

En total, la primera encuesta se aplicó a 585 estudiantes de siete licenciaturas de humanidades, mientras que la segunda encuesta se aplicó a 404 estudiantes en la conclusión de su primer año. ${ }^{5}$ Este seguimiento, permitió elegir a ciertos informantes clave, de manera que se entrevistaron a catorce estudiantes de las diferentes carreras, aquellos cuya participación había sido relevante ${ }^{6}$ en diversos eventos asociados con las protestas sociales formuladas en el contexto del área de humanidades. Estos estudiantes fueron entrevistados porque en cierta forma son portadores de un capital simbólico_constituido a partir de su rol como actores sociales estudiantiles. La adquisición de este capital es el reflejo de la socialización en el primer año de estudios universitarios. Cabe mencionar que mientras las encuestas se realizaron al

3- Se incluyen en el anexo 1 las dos encuestas. La primera corresponde a la aplicación inicial con estudiantes al momento de su ingreso a la universidad. Mientras que la segunda aplicada un año después, además de incluir los elementos de la primera, amplía las preguntas sobre el asunto de la socialización política.

4- Se incluye en el anexo 2 la guía de entrevista, la cual se orientó a indagar en los estudiantes las prácticas sociales, culturales y de participación política después de un año de cursar estudios universitarios.

5- La diferencia numérica con respecto a la primera encuesta se debe al abandono escolar que presentaron algunas carreras.

6- Por participación relevante se considera a los estudiantes que mostraron una alta frecuencia de participación en actividades de socialización política, quienes estaban involucrados en procesos y grupos relativos a la protesta social. Únicamente algunos fragmentos de las entrevistas más significativas fueron recuperados en este artículo. Por razones de confidencialidad, no mencionamos los nombres de los y las estudiantes, sino que los identificamos en el texto con un código: la letra $\mathrm{E}$ más el número de entrevista. Sus opiniones han sido transcritas respetando la forma original en la que fueron formuladas. 
ingreso y después de un año, las entrevistas se efectuaron a lo largo de seis semestres, ${ }^{7}$ intentando que los estudiantes asociaran su actividad social y política con el primer año en la universidad.

En el estudio general, se exploraron las dimensiones cultural, social y política que constituyen la vida estudiantil universitaria; sin embargo, en este artículo se dedicó mayor atención a las dos últimas dimensiones. Desde los estudios pioneros de Tinto (1987), es posible advertir que la escuela es un espacio escolar caracterizado por diversos sistemas, entre los que el autor destaca el académico y el social. Gracias a una amplia gama de investigaciones, entre las que se identifican los trabajos de Astin (1987), Pascarella y Terenzini (1991) y Torenbeek, Jansen y Hofman (2010), se reconoce la importancia del ambiente escolar tanto como el hecho de cursar el primer año de estudios universitarios. Asimismo, tiene relieve ubicar a las tres dimensiones señaladas como aquellas que giran alrededor de la condición de jóvenes de los estudiantes universitarios (De Garay, 2004; Weiss, 2012; Silva y Rodríguez, 2012).

En cada una de las dimensiones señaladas, se recuperó un conjunto de variables que permitió reconocer los cambios experimentados por los estudiantes de acuerdo con los supuestos iniciales presentados. Las dimensiones social y política (que es el modo utilizado para referirse a la participación en actividades de protesta social) constituyen una especie de socialización que se consideró pertinente porque aporta elementos para emprender el análisis planteado. En ese sentido, es posible hablar de una "socialización política" como una noción central a la que se dará seguimiento. Asimismo, se emplea otra noción, más empírica, para operacionalizar a la socialización política, a saber, la que constituyen los denominados grupos de pertenencia.

Los grupos de pertenencia, se definen como espacios de socialización donde los estudiantes adquieren ciertos patrones de conducta, códigos de comunicación, así como determinados valores generados por la convivencia. Es una noción construida por Merton, útil para identificar cómo entran los actores en contacto con otros, generando una interacción social específica (Merton, 1969).

Los grupos de pertenencia han sido el punto de partida de diversos trabajos que analizan el comportamiento de los sujetos en colectivos específicos (Vinck, 2012). Se utiliza esta noción porque a pesar de la distancia temporal que tiene su origen, sigue mostrando vigencia en cuanto al tipo de referentes analíticos que propone.

Los grupos de pertenencia, condensan metodológicamente las características para discutir la hipótesis planteada, así como para analizar la apropiación de los espacios universitarios por parte de los estudiantes tanto como la socialización que ellos despliegan en el primer año de estudios; en ese sentido, los grupos de pertenencia pueden considerarse como la unidad de análisis de este trabajo.

Los grupos de pertenencia aluden a un conjunto de prácticas sociales que realizan los estudiantes como actores en los diferentes escenarios de socialización y mediante los cuales constituyen a los grupos de referencia. Es decir, un grupo se conforma gracias a la participación de sus miembros, tanto como por la inversión de tiempo que éstos le dedican a determinadas temáticas según la orientación de cada grupo. De esta forma, la socialización de los estudiantes se define en determinados escenarios, con una interacción con otros estudiantes y en función de intereses específicos. Por tal razón, las prácticas socia-

7- En algunos casos fue más pertinente llevar a cabo las entrevistas tomando cierta distancia con el primer año de estudios, pues parte de los temas abordados giraban en torno a la represión que el Gobierno del Estado implementó para dar seguimiento a las acciones estudiantiles. Los entrevistados proporcionaban mayor información al "sentirse más seguros" en dicha distancia temporal. 
les y políticas pueden definirse como la unidad de medida o de registro de la participación en diversas actividades y escenarios o espacios sociales.

En la encuesta, se preguntó a la población cuáles eran los grupos en los que ellos habían participado de forma importante. Si bien la socialización es muy compleja y tiene componentes que pueden ser identificados únicamente con un seguimiento muy prolongado de la acción social de los actores estudiantiles, se consideró que la participación en agrupaciones permitiría tener al menos un panorama general de dicha socialización. Haciendo un cálculo en horas, definiendo el número de amigos dentro de cada grupo, así como la frecuencia de participación tanto presencial como en redes sociales, los estudiantes reportaron una variabilidad de grupos y escenarios de socialización.

Cada grupo reportado por los estudiantes contenía, a su vez, información sobre las actividades que ellos llevaban a cabo. Por ejemplo, en el caso de los grupos culturales/artísticos, se definió la participación en actividades artísticas, la asistencia a eventos culturales y otras actividades de consumo cultural (Cine, teatro, danza, orquesta sinfónica, conciertos de jazz, entre otras) tanto en el contexto de la escuela como fuera de ella. Pero también se consideró ser miembro de alguna agrupación en específico (Baile, danza, teatro, entre otras).

En lo referente a las agrupaciones deportivas, se consideraron todos los contextos de participación en grupos de esta índole. Los estudiantes señalaban no sólo la asistencia a eventos sino también el hecho de pertenecer a grupos específicos, dentro y fuera de la escuela.

En cuanto a los grupos políticos, se definió la participación tanto en las dinámicas de la política dentro de las carreras como fuera de ellas, poniendo especial énfasis en actividades de protesta social y señalando los distintos eventos en los que su presencia tuvo lugar. Así, la socialización política, está concebida como el contexto en el cual se adquiere una identidad participativa en los escenarios en los cuales los estudiantes son capaces de reconocer la importancia de su participación. Fue necesario distinguir los planos internos y externos a las instituciones escolares, porque la participación en actividades de socialización política son de naturaleza distinta: desde ser parte de los procesos de discusión y formulación de demandas con respecto a lo que ocurre dentro de la escuela, hasta formar parte de un grupo específico que se organiza para asistir a una marcha de protesta social con referencia a algún evento de índole más general y público.

De esta forma, al seguir por medio de la encuesta las prácticas de los estudiantes tanto en un plano interno como externo a las instituciones escolares, se obtuvo una secuencia de los grupos que ellos conformaron en el primer año de estudios universitarios, con lo cual se establecieron los cambios experimentados por ellos en ese periodo, al mismo tiempo que se identificó cómo fue incorporándose la participación en actividades de esa naturaleza.

Se construyó un perfil de socialización y de participación política. De este modo, se hizo un análisis de la socialización dentro y fuera del bachillerato y de la correspondiente dentro y fuera de la universidad. Cabe señalar que en el caso de la socialización política en el primer año universitario, se introdujo un matiz importante, al considerarse qué tan relevante fue la participación de los estudiantes, bajo el supuesto de que no todos desarrollaron sus prácticas con el mismo nivel de compromiso y frecuencia. Para ello, se establecieron dos categorías, que en su momento serán útiles para analizar con detalle la población de estudio; dichas categorías son Participación con cierta frecuencia y Participación en forma relevante. 
La categoría Participación con cierta frecuencia, se refiere a aquellos estudiantes que deciden formar parte, de manera temporal únicamente, de algunas actividades o eventos de protesta, formulando demandas específicas. Estos estudiantes, pueden asistir a eventos tales como marchas, plantones, formar comisiones de estudiantes para elaborar documentos de inconformidad ante las decisiones de las autoridades escolares o bien para integrar de manera temporal grupos de protesta en un sentido más general. Para ellos, el compromiso está orientado a mostrar cierta presencia como estudiantes, sin restarle prioridad a otros ámbitos dentro y fuera de la escuela (grupos de pertenencia y escenarios de socialización) y que también demandan algún tiempo.

Por su parte, la categoría Participación en forma relevante, hace referencia a los estudiantes que deciden que la participación en la socialización política es crucial y vale la pena invertir un tiempo considerable en ella. Tiene sentido el hecho de formar parte de grupos específicos, ser consejero alumno, o formar parte del equipo de la consejería; asimismo, estar en comunicación permanente con agrupaciones políticas fuera de la escuela, participar en movimientos sociales que van más allá de los que están en el alcance inmediato de su ambiente estudiantil, asistir a las reuniones de las asociaciones de estudiantes en un nivel más general, participar de la agenda política universitaria, entre otras cuestiones. Es decir, su participación es más permanente y comprometida que la del primer grupo.

Para integrar las experiencias internas y externas ${ }^{8}$ al ámbito escolar con referencia a la socialización política de los estudiantes, se construyó nuevamente una tipología. El siguiente esquema resume el procedimiento llevado a cabo.

\section{Esquema 1. Tipología de prácticas y políticas en el bachillerato} $y$ en el primer año universitario

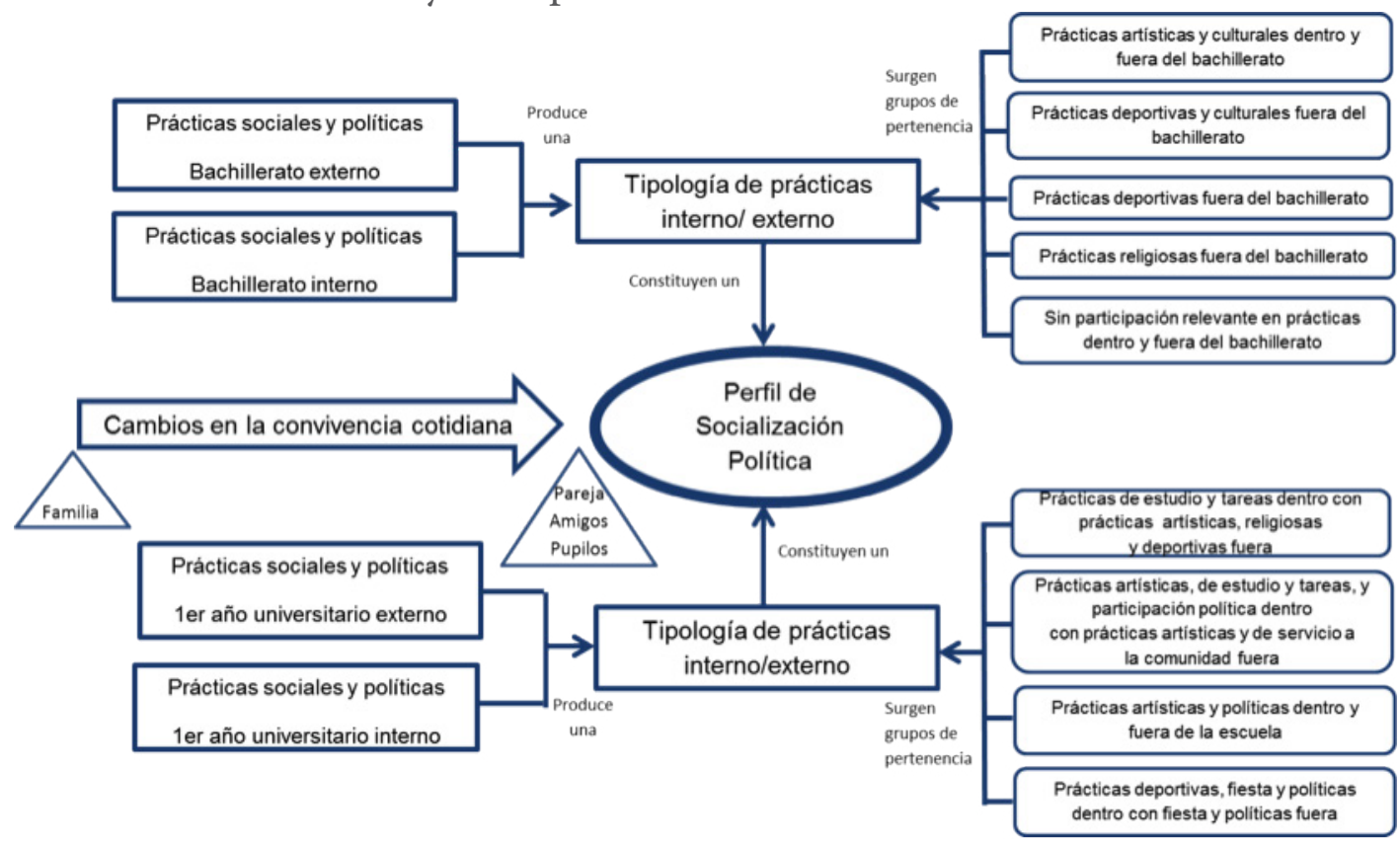

8- La integración de tales experiencias concibe que lo que ocurre dentro y fuera de la escuela puede separarse analíticamente, pero ambos planos están presentes de manera continua en la socialización. 


\section{Cómo llegaron los estudiantes a la Universidad Veracruza- na y qué cambios se reconocen en ellos después de un año}

Cuando los estudiantes ingresaron a la universidad tenían cierta condición socioeconómica, suficiente para considerar que contaban con los recursos básicos, al menos, para comenzar sus estudios superiores. La gran mayoría procedían de un núcleo familiar establecido. No habían tenido experiencias de participación en actividades de protesta social antes de ingresar a la universidad, ni tampoco habían formado parte de alguna agrupación cuyos fines fuera la actividad política. Se observan con detalle estos rasgos.

Tabla 1. Convivencia familiar previa al ingreso a la Universidad Veracruzana

\begin{tabular}{|lcccccc|}
\hline & $\mathbf{n}$ & $\begin{array}{c}\text { Núcleo familiar } \\
\%\end{array}$ & $\begin{array}{c}\text { Amigos o pareja } \\
\%\end{array}$ & $\begin{array}{c}\text { Pupilos } \\
\%\end{array}$ & $\begin{array}{c}\text { Otros familiares } \\
\%\end{array}$ & Total \\
\hline Datos generales & 585 & 92.6 & 1 & 1.2 & 5.1 & 100 \\
& & & & & & \\
Por carrera & & & & & & \\
Letras Españolas & 50 & 92 & 4 & 0 & 4 & 100 \\
Filosofia & 45 & 88.9 & 2.2 & 4.4 & 4.4 & 100 \\
Sociología & 58 & 89.7 & 1.7 & 1.7 & 6.9 & 100 \\
Historia & 63 & 93.7 & 1.6 & 1.6 & 3.2 & 100 \\
Lengua Francesa & 49 & 83.7 & 0 & 2 & 14.3 & 100 \\
Lengua Inglesa & 169 & 94.1 & 0.6 & 1.2 & 4.1 & 700 \\
Pedagogía & 151 & 96 & 0 & 0 & 4 & 700 \\
\hline
\end{tabular}

Siguiendo los matices de la primera tabla, se encuentra que prácticamente el total de la población tenía como origen social un medio familiar como el ámbito de pertenencia previo, si bien con algunas variantes (familia nuclear en el sentido clásico, familia monoparental, entre otros). Esta configuración es importante porque aporta un conocimiento de cómo llegaron a la universidad y dónde estaba el centro de su socialización.

Tabla 2. Convivencia durante el primer año de estudios universitarios

\begin{tabular}{|c|c|c|c|c|c|c|}
\hline & $\mathrm{n}$ & $\begin{array}{c}\text { Núcleo familiar } \\
\%\end{array}$ & $\begin{array}{c}\text { Amigos o pareja } \\
\%\end{array}$ & $\begin{array}{c}\text { Pupilos } \\
\%\end{array}$ & $\begin{array}{c}\text { Otros familiares } \\
\%\end{array}$ & Total \\
\hline Datos generales & 404 & 50.6 & 12.9 & 18.6 & 17.9 & 100 \\
\hline \multicolumn{7}{|l|}{ Por carrera } \\
\hline Letras Españolas & 35 & 46.9 & 18.4 & 24.5 & 10.2 & 100 \\
\hline Filosofia & 18 & 48.8 & 14 & 23.3 & 14 & 100 \\
\hline Sociología & 41 & 50.9 & 17 & 11.3 & 20.8 & 100 \\
\hline Historia & 21 & 67.8 & 10.2 & 13.6 & 8.5 & 100 \\
\hline Lengua Francesa & 41 & 28.9 & 26.7 & 11.1 & 33.3 & $\quad 100$ \\
\hline Lengua Inglesa & 117 & 44.2 & 10.2 & 25.2 & 20.4 & . 100 \\
\hline Pedagogía & 131 & 58.2 & 8.9 & 15.8 & 17.1 & 100 \\
\hline $\mathbf{N}=$ & 404 & & & & & \\
\hline
\end{tabular}


Se advirtió que un año después la situación cambió, la distribución que se aprecia en la tabla dos muestra una menor presencia del ámbito familiar en la convivencia cotidiana, pues cerca de la mitad de los estudiantes amplió su espectro de interacción al entrar en contacto con otras personas: amigos, parejas, compañeros de vivienda u otros familiares. Esta situación, desde luego, se relaciona con los desplazamientos geográficos de aquellos estudiantes cuyos lugares de origen se sitúan a una distancia considerable de Xalapa (más de 30 kilómetros), sobre todo si se recuerda que la diversidad estudiantil de la Universidad Veracruzana es muy alta. Tan solo en el área de humanidades, entre la población estudiada, se reconocieron más de 300 localidades de procedencia a lo largo del Estado de Veracruz. El cambio de residencia parece ser una primera característica de la construcción de una identidad participativa con referencia a la universidad.

\subsection{Durante el bachillerato, la socialización previa}

Se analiza ahora cómo se transformó la vida social de los estudiantes con el paso del tiempo. En principio, ellos se incorporaron a la Universidad mostrando un bajo perfil de socialización y de participación política construida y puesta en práctica durante el bachillerato. Este perfil pudo reconstruirse desde la encuesta al presentarles un amplio menú de escenarios de socialización y pedirles que eligieran aquellos que reconocían como relevantes. Al mismo tiempo, de forma complementaria, los estudiantes identificaron otros espacios que no habían sido considerados en las opciones de la encuesta.

En un primer análisis de la información obtenida, se seleccionaron únicamente los escenarios y grupos que tuvieron cierta relevancia. Con lo anterior, se identificó que dentro del espacio escolar -en el bachillerato- únicamente los contextos deportivos, la integración de una banda de guerra, los espacios o escenarios artísticos y culturales resultaron significativos. ${ }^{9}$ Esto permitió conocer que a pesar del tiempo que los estudiantes pasaban dentro de la escuela, no había una diversidad muy amplia de espacios sociales en los cuales reconocieran su participación.

Para algunos autores como Dubet (2000) el hecho de que los estudiantes tengan un alto nivel de inversión de su tiempo en la escuela, crea una "experiencia escolar" que es el resultado de una socialización prolongada en este espacio social. Si bien se parte de un acuerdo inicial con esta experiencia escolar, en nuestra población tanto los espacios como las prácticas asociadas a ellos no eran muy diversos.

Sin embargo se amplió el foco de atención a la socialización fuera del bachillerato, explorando prácticas de los estudiantes más allá de la escuela, encontrándose una configuración no muy distinta en cuanto a los grupos de pertenencia se refiere. Resultaron significativos los escenarios y prácticas religiosas, artísticas/culturales y deportivas. Es decir, el componente religioso fue el único que se identificó como un espacio nuevo en la exploración de ese plano externo.

Como se ha descrito en el esquema uno, al localizar los grupos de pertenencia más relevantes en los espacios sociales interno y externo con relación a la escuela, se procedió a elaborar una tipología de las prácticas desplegadas en ambos planos. Para ello, se utilizó la técnica de cluster k means, ${ }^{10}$ con la cual se

9- Con significativos queremos decir que al menos 15 por ciento de la población total participaba en ellos.

10- Esta técnica se utiliza comúnmente para construir categorías o tipos (tipologías) a través del mecanismo de agrupación de aquellos casos que tienen características comunes según los puntajes asignados a cada una de las condiciones que se están analizando. Las categorías resultantes son excluyentes. Esta técnica se realizó con el paquete SPSS. 
- Revista de Ciencias Sociales y Humanidades. ISSN-P: 0188-9834 ISSN-E: 2395-8669.

pudieron construir cinco tipos distintos de escenarios que combinaron prácticas sociales, como se ve a continuación.

Tabla 3. Tipología de escenarios y prácticas de socialización dentro y fuera del bachillerato

\begin{tabular}{|c|c|c|c|c|c|c|c|}
\hline & $\mathbf{n}$ & $\begin{array}{c}\text { Prácticas artisticas } \\
\text { y culturales dentro } \\
\text { y fuera del bach } \\
\%\end{array}$ & $\begin{array}{c}\text { Prácticas deportivas } \\
\text { y culturales } \\
\text { fuera del bach } \\
\%\end{array}$ & $\begin{array}{l}\text { Prácticas deportivas } \\
\text { fuera del bach } \\
\%\end{array}$ & $\begin{array}{c}\text { Prácticas religiosas } \\
\text { fuera del bach } \\
\%\end{array}$ & $\begin{array}{c}\text { Sin participación } \\
\text { relevante en prácticas } \\
\text { dentro y fuera del bach } \\
\%\end{array}$ & Total \\
\hline Datos generales & 564 & 18.4 & 18.6 & 16 & 2.8 & 44.1 & 100 \\
\hline \multicolumn{8}{|l|}{ Por carrera } \\
\hline Letras Españolas & 49 & 28.6 & 26.5 & 6.1 & 0 & 38.8 & 100 \\
\hline Filosofia & 42 & 14.3 & 14.3 & 31 & 4.8 & 35.7 & 100 \\
\hline Sociología & 56 & 25 & 12.5 & 12.5 & 1.4 & 48.2 & 100 \\
\hline Historia & 59 & 13.6 & 22 & 20.3 & 0 & 44.1 & 100 \\
\hline Lengua Francesa & 48 & 35.4 & 12.5 & 14.6 & 0 & 37.5 & ' 100 \\
\hline Lengua Inglesa & 164 & 15.9 & 16.5 & 19.5 & 4.3 & 43.9 & 100 \\
\hline Pedagogía & 146 & 13 & 22.6 & 11 & 4.1 & 49.3 & 100 \\
\hline$N=$ & 564 & & & & & & \\
\hline Nt_585 & & & & & & & \\
\hline
\end{tabular}

De acuerdo con la tabla tres, se destacan dos rasgos en la distribución de la población entre las categorías de análisis. En primer lugar, se observa que todas las carreras recibieron estudiantes cuya mayoría se ubicó en la categoría Sin participación relevante en prácticas dentro y fuera del bachillerato, cuando los estudiantes cursaban ese nivel. Es decir, ellos no invertían ni comprometían parte importante de su tiempo en alguno de los grupos en cuestión, seguramente su socialización se orientaba en otros ámbitos. Por lo tanto, la pertenencia no se presentaba como una condición de intercambio de códigos, valores, comportamientos sociales específicos, en esos escenarios de socialización.

El siguiente grupo se conformó mayoritariamente por quienes mantenían prácticas sociales de tipo artístico y cultural tanto dentro como fuera del espacio escolar. Para estos jóvenes, la socialización fuera de la escuela era como un continuum de aquella que experimentaban dentro de la institución escolar.

Un tercer grupo, estuvo representado por quienes realizaban prácticas culturales y deportivas únicamente fuera de la escuela. Este grupo llama la atención porque su dedicación a actividades dentro de la institución escolar no resultó relevante; puede suponerse que ellos cumplen con lo mínimo dentro de la escuela, porque su interés de interacción social está más allá de este espacio social.

Finalmente, en menor medida, se identificó un grupo con predominancia de prácticas religiosas, muy pequeño, y no combinaba éstas con otras prácticas sociales tales como aquellas que resultaron más representativas en la encuesta.

Como segundo rasgo de la tabla tres se tiene que, sumadas, las categorías que aludían a una socialización fuera del bachillerato, concentraron 37.4 por ciento del total de casos, es decir, uno de cada tres estudiantes invertía más tiempo fuera de la escuela en su interacción social. Esto quiere decir, que aun cuando la escuela es ese escenario de "construcción de sentido" que algunos autores señalan (Guzmán y Serrano, 2011; Weiss, 2012; Silva y Rodríguez, 2012), sin duda dicha construcción se articula con las experiencias sociales que los estudiantes viven fuera de la institución escolar. 


\subsection{Durante el primer año universitario, los cambios en la socialización}

Se consideran ahora los cambios en la socialización y constitución de grupos después del primer año de los estudios universitarios. Para ello, se retomó la pregunta acerca de la participación en grupos de referencia tanto dentro como fuera de la escuela, encontrándose esta vez que dentro del espacio escolar, las agrupaciones y prácticas más representativas fueron las de tipo empresarial, deportiva, artística, estudio y tareas, de servicio a la comunidad y representación estudiantil. Es decir, hubo un incremento de grupos de pertenencia y las consecuentes prácticas en cada uno de ellos; en este lapso, la socialización se diversificó.

No solo la entrada en contacto con nuevos actores caracterizó al primer año de estudios, sino también el hecho de formar parte de otras agrupaciones, dedicarles algún tiempo, interactuar con sus miembros a través de diversos medios presenciales y virtuales, así como intercambiar ciertos códigos y construir ciertas pautas de comportamiento y valores específicos que en su conjunto muestran la relevancia que tiene la vida estudiantil en este periodo para la mayoría de los jóvenes. La experiencia escolar, volviendo a la noción de Dubet, adquirió nuevos ordenamientos, se transformó y se volvió más compleja.

Desde luego, se exploraron también en la encuesta los grupos que resultaron relevantes fuera del contexto escolar. Esto reportó un nuevo menú de escenarios de socialización, identificándose que las agrupaciones empresariales, deportivas, artísticas, de fiesta, religiosas, políticas, de representación estudiantil y de estudio y tareas adquirieron sentido. Esta nueva configuración de la interacción social merece una mayor reflexión. Para establecer el análisis, se recurrió nuevamente al uso de tipologías, ocupando nuevamente la técnica de cluster k means, la cual arrojó cuatro grupos.

\begin{tabular}{|c|c|c|c|c|c|c|}
\hline & $\mathbf{n}$ & $\begin{array}{c}\text { Prácticas de estudio } \\
\text { y tareas dentro } \\
\text { con artísticas, religiosa: } \\
\text { y deportivas afuera } \\
\%\end{array}$ & $\begin{array}{c}\text { Prácticas artísticas, de estudio } \\
\text { y tareas, y participación } \\
\text { política dentro con } \\
\text { artísticas y de servicio } \\
\text { a la comunidad afuera } \\
\%\end{array}$ & $\begin{array}{l}\text { Prácticas artísticas } \\
\text { y políticas dentro } \\
\text { y fuera de la escuela }\end{array}$ & $\begin{array}{c}\text { Prácticas deportivas, } \\
\text { fiesta y politicas } \\
\text { dentro con fiesta y } \\
\text { politicas fuera } \\
\%\end{array}$ & Total \\
\hline Datos generales & 379 & 44.1 & 31.4 & 10 & 14.5 & 100 \\
\hline \multicolumn{7}{|l|}{ Por carrera } \\
\hline Letras Españolas & 26 & 42.3 & 34.6 & 7.7 & 15.4 & 100 \\
\hline Filosofia & 18 & 50 & 11.1 & 11.1 & 27.8 & 100 \\
\hline Sociología & 37 & 29.7 & 24.3 & 21.6 & 24.3 & 100 \\
\hline Historia & 18 & 27.8 & 22.3 & 22.2 & 27.8 & 100 \\
\hline Lengua Francesa & 39 & 38.5 & 43.6 & 12.8 & 5.1 & 100 \\
\hline Lengua Inglesa & 115 & 55.7 & 29.5 & 3.5 & 11.3 & 100 \\
\hline Pedagogía & 126 & 41.3 & 34.9 & 10.3 & 13.5 & . 100 \\
\hline $\mathbf{N}=$ & 379 & & & & & \\
\hline Nt_404 & & & & & & \\
\hline
\end{tabular}

De acuerdo con la tabla cuatro, el primer grupo se caracterizó por tener un conjunto de prácticas básicamente fuera de la universidad. Con excepción de su pertenencia a agrupaciones de estudio y tareas dentro de la escuela, sus miembros dedicaron la mayor cantidad de su tiempo a las prácticas deportivas, 
artísticas y religiosas, fuera de la escuela. Puede decirse que se trata de alumnos que cumplían con los requisitos escolares dentro de su carrera, pero no establecían una interacción más allá de las actividades que demandaban sus estudios.

El segundo grupo, cambió algunas dinámicas de socialización con respecto al anterior. Los estudiantes que se ubicaron aquí reportaron pertenencia a agrupaciones artísticas, de estudio y tareas y de representación estudiantil o participación política dentro de la escuela, al mismo tiempo que invirtieron buena parte de su tiempo en grupos artísticos y de servicio a la comunidad fuera de la universidad. El rasgo que llama la atención es la diversidad de grupos a los que pertenecían dentro de la institución.

El tercer grupo, se convirtió sin duda en uno de los que más información proveyó para los propósitos de este trabajo, pues aquí se ubicaron los estudiantes que solo participaban a través de prácticas artísticas y políticas tanto dentro como fuera de la escuela. La pertenencia a otras agrupaciones no tuvo mayor relevancia.

El cuarto y último grupo, por su parte, ubicó a los estudiantes con prácticas deportivas, artísticas, de fiesta y políticas dentro de la universidad, y únicamente prácticas políticas fuera de la universidad. Es decir, se trata de un conjunto de estudiantes que invirtieron la mayor cantidad de su tiempo dentro de la escuela, pues ahí se identificó con mayor peso su socialización, dejando para el plano de lo externo únicamente las prácticas políticas.

Las cuatro categorías presentan combinaciones en las cuales se observa que la socialización de los estudiantes se ubicó tanto en un plano interno como uno externo, si bien con predominio de alguno de los dos según la categoría en cuestión. Después de un año, los grupos de pertenencia se diversificaron, ${ }^{11}$ al mismo tiempo que la población de estudio se redujo si se compara con el tamaño que tenía al ingreso. Estas dos características intervinieron para que se diera una recomposición de la vida social de los jóvenes universitarios.

El primer grupo, señalado como aquel que reunió a quienes dedicaban más tiempo de socialización fuera de la universidad, resultó ser el más grande de todos los que constituyeron esta tipología. Poco menos de la mitad de la población se ubicó aquí. Los tres grupos restantes, se identificaron con un cierto equilibrio en cuanto a las prácticas que realizan tanto dentro como fuera de la escuela. Las prácticas externas a la escuela pueden definirse nuevamente como la continuación de la vida social de los estudiantes dentro de la universidad y particularmente dentro de sus carreras.

Un rasgo que llama la atención en la tabla, se refiere a las diferencias que hay entre las carreras de humanidades. La socialización no es solo un fenómeno que ocurra por decisión de los estudiantes como actores sociales, sino también por las características que encierra el ambiente escolar donde tiene relieve la orientación académica, social y cultural de cada carrera.

$\mathrm{Al}$ afinar el foco de análisis, puede advertirse que en las diversas combinaciones en cada grupo de la tabla, una de las prácticas que predominaron fue la de los escenarios artísticos y culturales. En casi todos los grupos se advierte que, ya sea como parte de un consumo cultural diversificado, o bien, como asistentes frecuentes a eventos culturales como el cine, el teatro, la danza, los conciertos de la

11- Vale aclarar que en el bachillerato (tabla tres) aparecen cinco grupos y en el primer año (tabla cuatro) aparecen únicamente cuatro. Sin embargo, uno de los grupos del bachillerato está constituido por una ausencia de participación. Al mismo tiempo, los cuatro grupos que se constituyeron en la tipología del primer año universitario presentan un mayor número de combinaciones en las prácticas sociales. 
orquesta sinfónica, las exposiciones artísticas, los conciertos de música, entre otros, la vida cultural estaba presente en los jóvenes universitarios después de un año. Estas prácticas han sido entendidas en la literatura correspondiente como una forma de apropiarse de los diversos bienes culturales que ofrecen la institución y los ámbitos por los que transitan los estudiantes (García Canclini, 1992; De Garay, 2004).

Con un peso aún mayor al que mostraron las prácticas culturales, se visualiza la presencia de las prácticas de participación de los estudiantes en la vida política tanto de la institución como fuera de ella. Se puede observar, que solo con excepción del primer grupo, el resto de las prácticas que reportaron los estudiantes combinó los escenarios de socialización y de participación política. Puede decirse que estos espacios de socialización estuvieron presentes con independencia de la inclinación de los estudiantes por algunas prácticas específicas, es decir, la participación en el contexto de la política se convirtió después de un año en una especie de escenario que se integró a la vida estudiantil de más de la mitad de estos actores universitarios. Esta nueva configuración sugirió el acercamiento a los aspectos específicos de este fenómeno social.

\section{Participación política, la apropiación de los espacios y las prácticas sociales de los estudiantes}

El primer año de estudios fue el contexto en el que tuvieron lugar nuevas experiencias de socialización en las trayectorias de los estudiantes. La participación en el ámbito de la vida política pasó a formar parte del comportamiento social de estos jóvenes. Es cierto que un sector importante no mostró el mismo perfil de participación; sin embargo, en la gran mayoría de ellos se aprecian cambios en ese sentido.

Se hizo un seguimiento de la población cuya participación fue más relevante en el ámbito de la política y de las protestas sociales. Para ello, se recuperaron los casos de aquellos estudiantes que se ubicaron en las últimas tres categorías de la tabla cuatro -anteriormente expuesta-. Como se recordará, hay 55.9 por ciento ( 212 casos) que se encontraban en esa condición. Ya sea que su participación en los escenarios de socialización estuviera orientada hacia las prácticas artísticas, deportivas o de fiesta, estos estudiantes se distinguían por el hecho de haber realizado prácticas de socialización política durante el primer año de estudios universitarios.

Al utilizar nuevamente los planos interno y externo con respecto a la escuela, se logró identificar de manera más puntual cómo se incorporaron las prácticas de socialización política en la vida de los jóvenes universitarios. Iniciando por el plano interno, la tabla cinco muestra los cambios mencionados. 
Tabla 5. Tipología de prácticas de socialización política dentro de la escuela en el primer año universitario

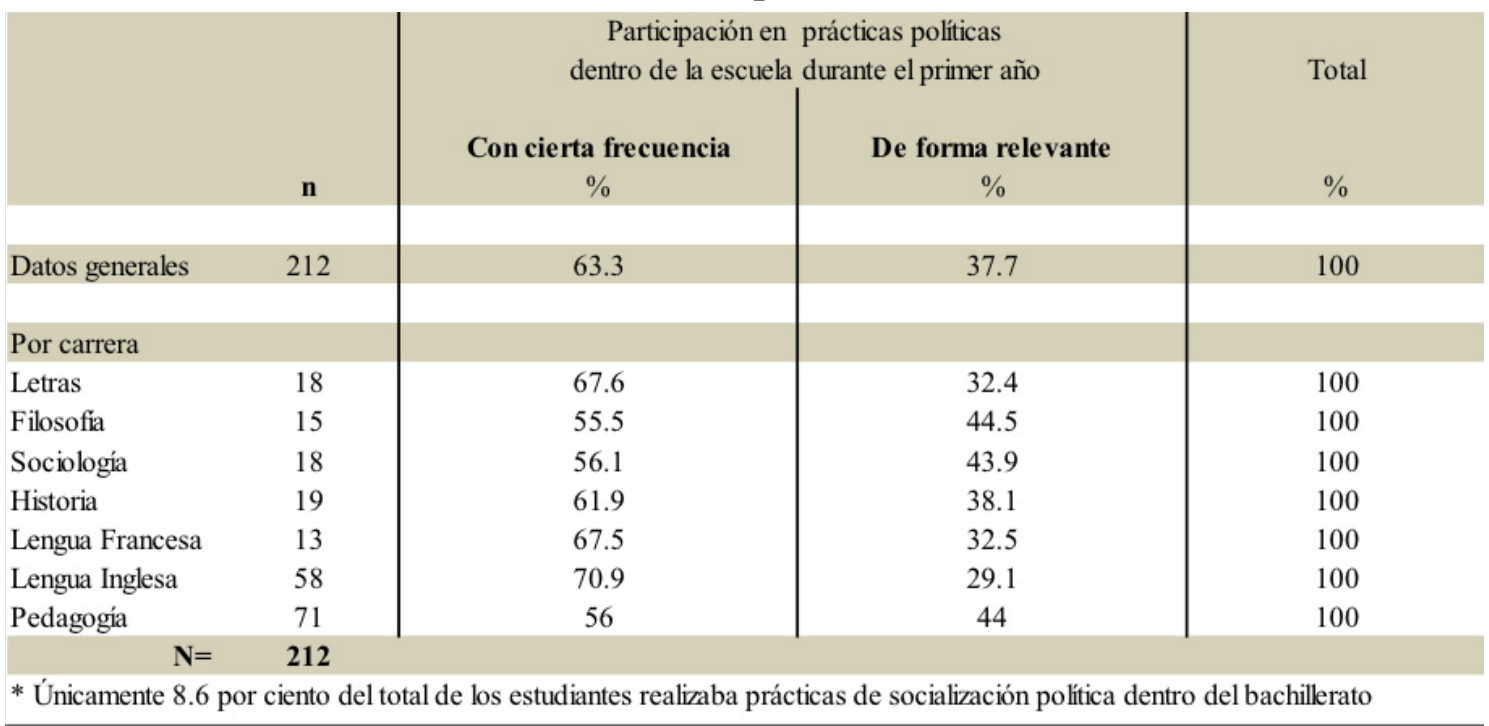

El primer rasgo encontrado en los estudiantes, y que constata algunos resultados anteriores, fue una baja participación en actividades políticas y de protesta social mientras ellos estudiaban en el nivel de bachillerato. En promedio, solo 8.6 por ciento de los estudiantes reportó haber participado en prácticas de este tipo dentro de la propia escuela. Sin embargo, hay una reconfiguración de sus prácticas un año después de haber iniciado la carrera.

Como se advierte en la tabla cinco, hay dos niveles de participación en las actividades de socialización política. La mayor proporción de estudiantes se ubicó en la categoría Participación con cierta frecuencia, que hace referencia a un compromiso temporal con diversos eventos en los que se considera que vale la pena hacer cierta presencia. Es un conjunto de estudiantes que no permaneció ajeno a las prácticas de socialización política. El fragmento siguiente, ilustra parcialmente esta reflexión cuando se preguntó a una estudiante cuáles eran los escenarios en los que ella había participado, o bien, si pertenecía a alguna agrupación específica dentro de la universidad o al menos dentro de la carrera en la cual estudiaba:

En la escuela hemos participado de distintas maneras....adentro de la escuela como dice Usted creo que una de las más importantes fue la de recientemente nuestra manifestación por la inconformidad ante el cambio de plan de estudios sin que a los estudiantes se les notificara cuáles iban a ser estas reformas... igual que muchos compañeros yo no pertenezco a alguna agrupación, a veces apoyo las decisiones de la consejería, aunque a veces no estoy de acuerdo...creo que es importante que como estudiantes no se pierda el interés por dar nuestra opinión, que nos tomen en cuenta, como lo del plan de estudios y las decisiones de imposición...no creo que haya que pertenecer a algún grupo para dar nuestra opinión sobre lo que pasa y nos puede afectar incluso en el momento en que salgamos de la carrera (E13).

Algunos autores señalan que a menudo los espacios escolares albergan una micropolítica en la cual se ponen en juego múltiples intereses que se manifiestan mediante la tensión y el conflicto (Ball, 1994). Sabedores de la posesión de un conjunto de recursos, los actores buscan el dominio de las denominadas zonas de incertidumbre, aquellos espacios en los cuales las reglas de juego no son tan claras o permiten 
que la acción social se produzca sin los constreñimientos objetivos que marcan dichas normas (Crozier y Friedberg, 1990). La siguiente opinión, en cierta forma da cuenta de un ambiente donde el conflicto parece caracterizar el escenario de negociación en el contexto escolar.

En el segundo semestre me ocurrió una experiencia desagradable, tuve una discusión con un maestro, me llevó a que tuviera que llegar otro maestro, como intermediario a solucionar el problema, con lo cual me dije, algo no está bien en la carrera me gustaría mejorar, así que comencé en el tercer semestre a participar, primero en las discusiones con los compañeros de la facultad, entre las horas libres, en el área de humanidades, lo cual me llevó a conocer a chicos de antropología, historia, sociología. Las opiniones de los compañeros, a veces desfavorables, me hacían ir a los textos que nos enseñaban en la carrera: Freyre por ejemplo, y leer cosas para tener elementos con los cuales discutir (E5)

La opinión anterior, muestra que no necesariamente la participación en la vida social y política de la institución escolar es una decisión consciente. Un evento cotidiano como lo es la entrada en conflicto con otros actores universitarios, puede devenir en otros como la construcción de un interés por una participación más relevante en este ámbito; incluso, puede ser un detonante que propicie la socialización con otros actores.

Al volver a la distribución de la tabla cinco, esta vez atendiendo la categoría Participación en forma relevante, se encontró que algunos estudiantes expresaron puntos de vista que dieron paso a otras posibilidades en el análisis emprendido. En esta categoría se observa que, en términos generales, uno de cada tres estudiantes tuvo una participación más allá de las eventuales actividades de protesta social. Este sector encontró en el espacio social de humanidades los escenarios propicios para involucrarse en los eventos a los cuales ellos les otorgaron algún sentido de relevancia. El siguiente comentario se orienta en esa dirección:

Fui consejero alumno cuando iba de quinto a séptimo semestre, anteriormente había participado en manifestaciones, era una persona muy activa y eso me llevó a la consejería, anteriormente, me refiero al segundo semestre de la carrera, antes de eso no estaba familiarizado con los movimientos sociales, los seguía por la televisión, por ejemplo me marcó mucho el fobaproa en el 99, yo escuchaba que mi papá le decía a mi mamá: el gobierno rescata a los banqueros pero nosotros no tenemos dinero (E5).

Las opiniones presentadas constituyen solo una mínima parte de la diversidad de argumentos que los estudiantes son capaces de esgrimir y presentar como una forma de mostrar la legitimidad que ellos reconocen en su situación de actores sociales. Se seleccionaron solo algunos de ellos, con la finalidad de ilustrar cómo los planos interno y externo pueden observarse analíticamente, aun cuando forman parte de una totalidad de experiencias en la vida de estos jóvenes.

En la distribución que se presenta en la tabla cinco, otro aspecto pertinente se refiere a cómo se ordenan los porcentajes en la categoría Participación en forma relevante según la carrera en cuestión. De este modo, Filosofía, Sociología y Pedagogía, tienen el mayor número de estudiantes que reportaron haber participado con mayor frecuencia en los escenarios señalados.

La distribución de las tres carreras mencionadas anteriormente, hace suponer que en ellas existen ciertos patrones de socialización, elementos y dinámicas de los cuales se apropian los estudiantes mediante prácticas de participación en la vida política, mediante la pertenencia a alguna agrupación, desempeñando un rol específico (como la consejería estudiantil) o bien haciendo presencia en algún evento específico. En esta interacción social, tanto la convivencia con otros actores sociales como la orientación 
ideológica y política de cada carrera tienen lugar en la construcción de la identidad participativa.

Se observa ahora la composición de la participación en actividades de socialización política en un plano externo a la institución universitaria. De acuerdo con la tabla seis, el primer rasgo a destacar es que la distribución en el peso e intensidad de participación es muy similar a la de la perspectiva interna; es decir, nuevamente se tiene que aproximadamente uno de cada tres estudiantes participó en forma relevante en actividades de socialización política fuera de la escuela, mientras que el resto reportó una participación un tanto menor.

Tabla 6. Tipología de prácticas de socialización

fuera de la escuela en el primer año universitario

\begin{tabular}{|c|c|c|c|c|}
\hline \multirow{2}{*}{\multicolumn{2}{|c|}{$\mathbf{n}$}} & \multicolumn{2}{|c|}{$\begin{array}{l}\text { Participación en prácticas politicas } \\
\text { fuera de la escuela durante el primer año }\end{array}$} & \multirow{2}{*}{$\begin{array}{c}\text { Tota } \\
\%\end{array}$} \\
\hline & & $\begin{array}{c}\text { Con cierta frecuencia } \\
\%\end{array}$ & $\begin{array}{c}\text { De forma relevante } \\
\%\end{array}$ & \\
\hline Datos generales & 212 & 66.5 & 33.5 & 100 \\
\hline \multicolumn{5}{|l|}{ Por carrera } \\
\hline Letras & 18 & 68.5 & 31.5 & 100 \\
\hline Filosofia & 15 & 66.6 & 33.4 & 100 \\
\hline Sociologia & 18 & 51.2 & 48.8 & 100 \\
\hline Historia & 19 & 47.7 & 52.3 & 100 \\
\hline Lengua Francesa & 13 & 75.7 & 24.3 & 100 \\
\hline Lengua Inglesa & 58 & 82.9 & 17.1 & 100 \\
\hline Pedagogía & 71 & 72.7 & 27.3 & 100 \\
\hline $\mathbf{N}=$ & 212 & & & \\
\hline
\end{tabular}

La semejanza entre ambas tablas, muestra que hay cierta consistencia en el modo en el que los estudiantes se plantean la participación en las actividades de socialización política, pero refleja aún más, ese continuum entre la vida dentro y la vida fuera de la escuela. La participación fuera de la escuela, está dada con referencia a la experiencia dentro de la misma, no se trata de procesos separados, son parte de las expresiones que adopta el hecho de haber construido una identidad estudiantil en escenarios distintos, pero que tienen el mismo punto de partida.

En la categoría participación con cierta frecuencia, se observa que dos tercios de la población se concentraron ahí, pero llama la atención que al tratarse de un plano externo haya casi la misma proporción de estudiantes que en el plano interno. El siguiente fragmento amplía la apreciación con respeto a lo externo e interno.

En el segundo semestre intentamos actividades para ayudarnos en las clases, lo cual me llevó a conocer a compañeros fuera de mi facultad...esto nos ayudó para saber de los movimientos como el de los colectivos de humanidades...participé varias veces, cerramos la facultad, hicimos que el rector se presentara una vez a atender nuestras demandas...mandaron dos veces al encargado de los asuntos estudiantiles y al director de humanidades y nos negamos a hablar con ellos...esa vez buscábamos mejorar las condiciones de la escuela, los espacios y los muebles, pues humanidades parecían salones descuidados como si no fueran de la universidad...creo que nos hicieron caso porque ya habíamos mostrado que po- 
díamos formar parte de otras cosas, de otros movimientos, ya se sabía en los periódicos de nosotros (E4).

La opinión vertida, aporta nuevos elementos. Lo interno y lo externo se vinculan de un modo en el que la legitimad adquirida por los estudiantes dentro de la universidad, puede pasar por la vía de la participación en movimientos o actividades de socialización política fuera de ella, es decir, se les reconoce dentro de la institución porque ellos han estado presentes en eventos fuera de la misma.

De igual forma, en la categoría Participación en forma relevante, se vuelve a apreciar que la distribución porcentual no varía mucho con respecto a la que se observó en la perspectiva interna. Es decir, una vez que los estudiantes se involucran con algún nivel de compromiso en la vida social y política, esta es capaz de ampliarse hasta el contexto externo casi con la misma fuerza con la que se presentó dentro de la escuela. La siguiente opinión de un estudiante, remite a esta reflexión.

En el tercer semestre me integré mucho con un movimiento de reforma laboral que había en el área de humanidades, participé con los compañeros y comencé a socializar con todos los estudiantes que estaban en ese movimiento, de Pedagogía, de Filosofía, de Antropología, mmm, creo que también había de Letras...antes de eso, no socializaba mucho con los compañeros, pero después de eso hice amigos tanto en la facultad como con otros fuera de la escuela...esto también me llevó a conocer la forma en que se organizaban otros movimientos, más allá de los que yo conocía en la escuela (E9).

Sin duda, la categoría Participación en forma relevante, permite también hacer un seguimiento del nivel de involucramiento y compromiso que puede alcanzar el hecho de ser estudiante, pertenecer a movimientos de protesta social y, en suma, tener presencia en el ámbito de la socialización política. El siguiente fragmento nos ayuda a reforzar este argumento:

El 13 de septiembre participamos con el CNTE y el magisterio para cerrar escuelas secundarias y primarias...ese mismo día desalojaron a los profesores en la plaza Lerdo, golpearon a los maestros. Yo fui a la plaza Lerdo para reforzar a los maestros, fui con un compañero de pedagogía y dos de idiomas, nos quedamos hasta el 14 en la madrugada, representantes del gobierno nos amenazaron y nos dieron media hora para desalojar. Los elementos de seguridad pública con perros, escudos, se nos van a los golpes, me dieron electrochoques...cuando me escondí en un callejón, en una casa donde había como 100 maestros escondidos...esto me ayudó posteriormente a llegar a la consejería (E5).

De acuerdo con los diversos fragmentos presentados en torno a las opiniones de los estudiantes, se observa que la participación estudiantil en la vida política, produjo una socialización donde lo interno y externo aparecen de manera complementaria. Los efectos producidos por el primer año universitario sin duda se aprecian en el comportamiento estudiantil, a tal grado que estos actores pueden llegar a construir un sentido de pertenencia donde se considera que tiene alta trascendencia formar parte de la protesta social.

En última instancia, hay un reconocimiento de los espacios sociales y éstos se interpretan como reductos desde donde vale la pena invertir tiempo y combinar las prácticas sociales, artísticas, culturales, deportivas y de fiesta con las propias de la vida política. La socialización política se convirtió durante el primer año en una especie de contexto de prácticas que aparecen como transversales en la vida de los estudiantes, pues tienen una presencia importante con independencia de las orientaciones que ellos le dan a su convivencia con otros actores universitarios. 


\section{Conclusiones}

De acuerdo con los resultados presentados, hay elementos suficientes para iniciar una breve discusión sobre la forma en cómo el primer año universitario se convirtió en un periodo de alta trascendencia para muchos estudiantes. Si bien una parte de la población que ingresó no tuvo el mismo nivel de participación en las actividades de socialización política que la mayoría de aquellos que permanecieron en la Universidad un año después de su ingreso, se han encontrado datos que revelan cambios visibles en estos actores sociales.

La entrada en contacto con un espacio simbólico como el de humanidades, con una importante legitimidad en el ámbito de las protestas sociales, devino en el hecho de que buena parte de la población estudiantil reconociera a esa área como el contexto propicio para iniciar una socialización política, novedosa, desconocida antes de formar parte de la institución universitaria.

A decir de Touraine (2013), es precisamente este fenómeno el que lleva a proponer la sustitución de la vieja concepción de actores sociales por una nueva forma de constituirse como tales, argumentando que la primera se refiere a su participación en la visión conjunta de las sociedades, cuestión que ha ido desapareciendo. La nueva noción de actores sociales puede dar paso a la de actores morales, articulados a partir de la idea de ocupar los espacios institucionales con la finalidad de manifestarse, conformar una protesta, asistir a los eventos donde pueden hacer pública su opinión, siempre en referencia a las situaciones de desigualdad que promueven el estado y otras élites de poder social.

En la hipótesis planteada en un inicio, se propuso que los estudiantes eran sujetos con una capacidad altamente receptiva, jóvenes susceptibles de recibir una influencia de otros actores y ambientes que anteriormente no eran reconocidos por ellos o simplemente estaban fuera de su alcance cuando aún no pertenecían a la universidad. En cierta forma, se ha dado cuenta de una socialización que produce una regulación en su comportamiento social y político. En ese sentido, se advierte que el planteamiento acerca de la construcción de un sentido de pertenencia a un ámbito altamente legítimo se orientaba en una dirección bastante aproximada a los supuestos iniciales.

En efecto, se puede decir que después de observar los cambios que se produjeron entre el tiempo que transcurrió desde el ingreso a las distintas carreras de humanidades hasta un año después, se presentaron algunos patrones de socialización que permiten verificar que los estudiantes se han apropiado de los espacios universitarios, definiendo como válidos los fenómenos sociales que se presentan en ellos y formando parte de los mismos.

Los datos recuperados en la encuesta mostraron que parte de los cambios producidos en el primer año de estudios comenzaron cuando los estudiantes tomaron cierta distancia geográfica con la socialización familiar. La entrada en contacto con otros actores universitarios, el hecho de contar con nuevos referentes de vida cotidiana en este periodo, dio origen a otras dinámicas.

De igual forma, a través del seguimiento de los grupos de pertenencia, las prácticas llevadas a cabo en cada uno de ellos, así como el nivel de socialización según cada grupo en cuestión permitió advertir un incremento en los escenarios de socialización, donde gradualmente la conformación de grupos y el despliegue de prácticas de participación política adoptaron nuevas formas.

Un rasgo que explica a la socialización política consiste en que ésta aparece como interconectada a 
otras dimensiones sociales de la vida estudiantil. Se combina con otras prácticas y otros escenarios. En ese sentido, se afirma que la socialización política no se da en una forma "pura" o "aislada". Con independencia de los intereses de los estudiantes para conformar diversos colectivos de manera temporal o permanente -grupos en los cuales se recrean las prácticas deportivas, artísticas, de fiesta, de estudio y tareas, empresariales, de participación en la comunidad, entre otras-, se observa una gradual construcción social relativa a la participación en la vida política, de ahí que puedan definirse como "prácticas transversales", pues se combinan con otras prácticas y orientaciones específicas.

$\mathrm{Al}$ incremento en los grupos de pertenencia y a la diversificación de las prácticas durante el primer año, hay que agregar la forma en cómo se presentó el plano interno y externo de participación política. Analizar ambos planos permitió visualizar al menos tres vías distintas mediante las cuales se construyó una identidad participativa entre la población objeto de estudio.

La primera vía está documentada y prevista en nuestra hipótesis. Los estudiantes arriban a los espacios universitarios, se involucran en las dinámicas de la protesta social y de la vida política y se manifiestan con respecto a los diversos eventos que tienen lugar dentro de la escuela. Este es el caso presentado en el fragmento de la entrevista trece, donde vale la pena manifestarse y expresar las inconformidades por el papel de las autoridades dentro de la carrera, pero solo a cuenta de haber socializado primero en este ámbito.

La segunda vía, más compleja y novedosa, aparece como una ruta en la cual ellos obtienen una legitimidad como actores sociales estudiantiles, participan en los eventos de la vida política dentro de la escuela, pero estos eventos sirven a su vez para construir una identidad participativa fuera de la escuela, entrando en contacto con otros actores y otros movimientos sociales. Es el caso del fragmento de la entrevista cinco, donde se plantea que la pertenencia a colectivos dentro del área de humanidades condujo a la entrada en contacto con otras agrupaciones sociales fuera de la universidad.

Finalmente, en una tercera vía, los estudiantes han construido un perfil de participación política, han generado ya un capital simbólico importante y este es utilizado nuevamente dentro de los espacios escolares; es decir, su participación en los eventos fuera de la escuela, les permite tener mayor presencia dentro de la institución universitaria. Los fragmentos de la entrevista cuatro dejan ver esta cuestión, pues se expone que la formulación de demandas sobre el mobiliario y las condiciones de infraestructura del área de humanidades tuvieron efecto gracias a que ellos ya se consideraban actores visibles, ya se sabía de ellos en diversos medios, razón por la cual demandan la presencia del Rector con la finalidad de establecer un diálogo con él, siendo esta la única forma aceptable por los estudiantes para resolver el conflicto, en este caso el cierre de las instalaciones. Descubrir que existen varias vías que van abriendo paso a la construcción de una identidad participativa fue posible gracias al punto de vista de los estudiantes entrevistados. Es importante observar, que a pesar de que hay diversas posibilidades de participación política, el punto de partida de esta construcción de identidad tiene su origen dentro de la escuela, aun cuando sus efectos trasciendan sus límites. Es posible que ese origen a veces esté fuera de los límites de una decisión racional de parte de los estudiantes, como sugiere el fragmento de la entrevista cinco, la entrada en conflicto con un profesor despertó el interés de un estudiante para involucrarse en la vida política de la escuela.

En el mismo orden de ideas, se encuentra que la entrada en contacto con los escenarios y contextos de socialización política se da mediante determinadas interacciones y reconocimientos de ciertos espacios; es decir, en ningún caso de la población estudiada encontramos que los estudiantes interpretaran 
la participación en los grupos y movimientos como una posibilidad de ingresar a partidos políticos $\mathrm{u}$ otras instancias institucionalizadas. Este fenómeno es importante porque independientemente de la vida futura de estos actores sociales, ellos están en un momento de su vida en el que su participación y su condición es legítima. Esto quiere decir que por ahora, la "cooptación política", ${ }^{12}$ práctica tan arraigada en la cultura política mexicana, no ha formado parte de las dinámicas de socialización estudiantil, al menos en el primer año.

Finalmente, merece la atención el hecho de que las distribuciones encontradas en las tablas cinco y seis, nos hayan mostrado diferencias importantes en la manera en cómo se ubican los estudiantes según la carrera en cuestión. Las carreras de Historia, Sociología, Filosofía y Pedagogía, reportaron la mayor proporción de estudiantes con un nivel alto de involucramiento en las prácticas políticas. Por su parte, Lengua Inglesa, Lengua Francesa y Letras Españolas, tuvieron la mayor parte de los estudiantes con una participación menos comprometida pero no ajena a los eventos de socialización política. De esta forma, la identidad participativa pasa por el reconocimiento de las características de los ambientes escolares, su orientación específica con respecto al conocimiento que producen y transmiten, las interacciones con otros compañeros y colegas.

Los ambientes escolares, son sin duda parte de esa relación entre la acción y la estructura que ha caracterizado a algunas ciencias sociales, tales como la sociología: esto es claro, al menos en los resultados mostrados, los sujetos (plano de la acción) entran en contacto con las instituciones (plano de las estructuras) las ocupan, las reconocen, adquieren sentido para ellos, construyen una identidad participativa y, con el paso del tiempo, muestran la influencia recibida por ellas. Las prácticas desplegadas por los actores, refuerzan, modifican y le otorgan nuevos atributos a esos espacios simbólicos que representan las estructuras institucionales, perpetuando así la legitimidad que éstas han acumulado a lo largo de su historia.

\section{Referencias}

Astin, Alexander.1997. What's Matters in College. San Francisco: Jossey Bass Publishers.

Ball, Stephen. 1994. La micropolítica de la escuela. Hacia una teoría de la organización escolar. México: Paidós.

Bauman, Zigmunt. 2013. Vida de consumo. México: FCE.

Bourdieu, Pierre y Löic Wacquant. 1995. Respuestas. Por una antropología reflexiva. México: Grijalbo.

Crozier, Michael y Erhard Friedberg. 1990. El actor y el sistema. México: Alianza Editorial.

De Garay, Adrián. 2004. Integración de los jóvenes en el sistema universitario. México: Pomares.

Dubet, Francois. 2000. En la escuela. Sociología de la experiencia escolar. México: Losada.

García, Néstor (Coord.). 1992. El consumo cultural en México. México: CONACULTA.

Giddens, Anthony. 2003. La Constitución de la sociedad. Bases para una teoría de la estructuración. Argentina: Amorrortu.

12- En la cultura política mexicana se entiende por cooptación política, la práctica de coaccionar a los actores políticos con el objetivo de anular su capacidad de oposición, mediante el uso de prebendas, puestos políticos, entre otros. 
Guzmán, Carlota y Olga Serrano. 2011. Las puertas del ingreso a la educación superior: el caos del concurso de selección a la licenciatura de la UNAM. Revista de la Educación Superior, 40(157): 31-53.

Habermas, Jürgen. 1999. Teoría de la acción comunicativa I. España: Taurus.

Lipovetsky, Gilles. 1983. La era del vacío. España: Anagrama.

Merton, Robert. 1969. Teoría y estructura sociales. México: Fondo de Cultura Económica.

Pascarella, Ernest y Patrick Terenzini. 1991. How college affect student. Eu: Jossey Bass Publishers.

Silva, Marisol y Adriana Rodríguez. 2012. El primer año universitario entre jóvenes provenientes de sectores de pobreza: un asunto de equidad. México: Asociación Nacional de Universidades e Institutos de Educación Superior.

Tinto, Vicent. (1987). El abandono de los estudios superiores: Una nueva perspectiva de

las causas del abandono y su tratamiento. México: UNAM, ANUIES.

Torenbeek, Marjolein, Ellen Jansen y Adriaan Hofman. 2010. The effect of the fit between secondary and university education on first-year student achievement. Studies in Higher Education, 35(6): 659-675. DOI: http://dx.doi.org/10.1080/03075070903222625

Touraine, Alain. 2013. Después de la crisis. México: FCE.

Vinck, Dominique. 2012. Ciencias y sociedad. Sociología del trabajo científico. España: Gedisa.

Weiss, Eduardo (Coord.). 2012. Jóvenes y bachillerato. México: Asociación Nacional de Universidades e Institutos de Educación Superior.

\section{Anexo 1}

Encuesta para estudiantes de nuevo ingreso

Estimado estudiante, esta encuesta ha sido diseñada para conocer las prácticas sociales, culturales y académicas que acostumbras a realizar dentro y fuera de la escuela, su aplicación tiene como único propósito conocer algunas características de ti, para tener información útil sobre aquello que ocurre en la vida de los estudiantes que ingresan a la Universidad Veracruzana. Tu apoyo es muy valioso, por lo que te suplicamos leas detenidamente las instrucciones y contestes las preguntas con información real.

Nombre: Matrícula:

Facultad: $\quad$ Correo electrónico:

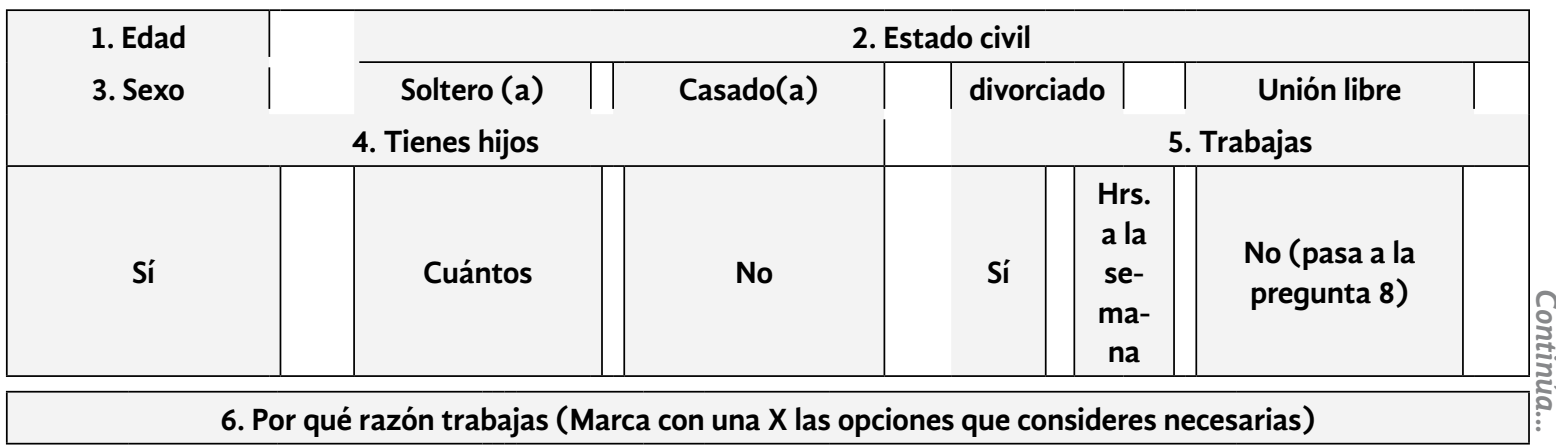




\begin{tabular}{|c|c|c|c|c|}
\hline \multicolumn{2}{|c|}{ Pagar mis estudios } & $\begin{array}{l}\text { Ayudar } \\
\text { al gasto } \\
\text { familiar }\end{array}$ & Sostener a mi familia & \\
\hline \multicolumn{2}{|c|}{ Adquirir experiencia laboral } & \multicolumn{2}{|c|}{$\begin{array}{l}\text { Tener independencia económica respecto de mi } \\
\text { familia }\end{array}$} & \\
\hline \multicolumn{5}{|c|}{ 7. Tu trabajo tiene relación con la carrera que vas a estudiar (señala en qué trabajas) } \\
\hline Sí & No & $\begin{array}{c}\text { Mi } \\
\text { trabajo } \\
\text { consiste } \\
\text { en }\end{array}$ & & \\
\hline
\end{tabular}

\begin{tabular}{|c|c|}
\hline $\begin{array}{c}\text { 8. En qué lugar vivías cuando cursaste el bachillerato } \\
\text { (señala población y estado) }\end{array}$ & $\begin{array}{c}\text { 9. En qué lugar vivirás una vez que ingreses a la UV } \\
\text { (señala población) }\end{array}$ \\
\hline & \\
\hline
\end{tabular}

\begin{tabular}{|l|l|c|c|}
\hline \multicolumn{3}{|c|}{ 10. En qué bachillerato estudiaste (asigna una respuesta por cada opción del menú) } \\
\hline Localidad de la Escuela & $\begin{array}{c}\text { Pública o } \\
\text { Privada }\end{array}$ & Estado & \\
\hline Nombre de la Escuela & & &
\end{tabular}

11. En los años en que estudiantes el bachillerato, quien se encargaba de la economía de la casa

\begin{tabular}{|c|c|c|c|c|c|c|}
\hline \multicolumn{6}{|c|}{ 11. En los años en que estudiantes el bachillerato, quien se encargaba de la economía de la casa } \\
\hline Padre o tutor & Madre o tutora & $\begin{array}{c}\text { Padre y madre o tutor y } \\
\text { tutora }\end{array}$ & Yo me encargaba & \\
\hline Hermanos & Otros familiares & & Otros, especifica & & \\
\hline
\end{tabular}

12. Cuál es la profesión de tus padres o tutores (asigna una respuesta por cada opción del menú)

\begin{tabular}{|c|c|c|}
\hline \multicolumn{2}{|c|}{ 12. Cuál es la profesión de tus padres o tutores (asigna una respuesta por cada opción del menú) } \\
\hline $\begin{array}{c}\text { Padres o tutores } \\
\text { Actividad }\end{array}$ & Padre o tutor & Madre o tutora \\
\hline Profesión & & \\
\hline $\begin{array}{c}\text { Ámbito en el que ejerce su profesión } \\
\text { (Ejemplos: oficina, empresa, fábrica, campo, } \\
\text { escuela, negocio, etc.) }\end{array}$ & & \\
\hline $\begin{array}{c}\text { Cargo que ocupa (maestro, jefe de oficina, } \\
\text { director, empleado, obrero, etc) }\end{array}$ & & \\
\hline
\end{tabular}

13. Señala el nivel máximo de escolaridad alcanzado por tus padres o tutores (señala un nivel por cada uno de ellos)

\begin{tabular}{|c|c|c|}
\hline $\begin{array}{l}\text { Padres } \\
\text { Nivel de estudios }\end{array}$ & Padre o tutor & Madre o tutora \\
\hline \multicolumn{3}{|l|}{ Sin estudio } \\
\hline \multicolumn{3}{|l|}{ Primaria incompleta } \\
\hline \multicolumn{3}{|l|}{ Primaria completa } \\
\hline \multicolumn{3}{|l|}{ Secundaria incompleta } \\
\hline \multicolumn{3}{|l|}{ Secundaria completa o equivalente } \\
\hline Bachillerato o equivalente incompleto & & \\
\hline
\end{tabular}




\begin{tabular}{|c|l|l|}
\hline Bachillerato o equivalente completo & & \\
\hline Estudios técnicos de posbachillerato & & \\
\hline Técnico Superior Universitario & & \\
\hline Normal & & \\
\hline Licenciatura incompleta & & \\
\hline Licenciatura completa & & \\
\hline Posgrado & & \\
\hline Lo ignoro & & \\
\hline Otro, especifica & & \\
\hline
\end{tabular}

14. Si tu padre o madre realizaron estudios de educación superior, qué licenciatura cursaron (señala una licenciatura por cada uno de tus padres)

Padre o tutor
Madre o tutora

\begin{tabular}{|c|c|c|c|c|c|}
\hline \multicolumn{6}{|c|}{ Tv de paga (especifica) } \\
\hline Megacable & Sky & \multicolumn{2}{|c|}{ Dish } & Otro(especifica) & \\
\hline Auto de la familia & \multicolumn{2}{|c|}{ Lavadora } & DVD & \multirow{2}{*}{\multicolumn{2}{|c|}{\begin{tabular}{|c|c|} 
& $\begin{array}{c}\text { Videojue- } \\
\text { gos }\end{array}$ \\
Horno de Microon- \\
das
\end{tabular}}} \\
\hline Celular propio & \multicolumn{2}{|c|}{ Auto propio } & Teléfono & & \\
\hline Computadora & Internet & $\begin{array}{l}\text { Impre- } \\
\text { sora }\end{array}$ & \multicolumn{3}{|c|}{$\begin{array}{l}\text { Libros de cultura general (enciclo- } \\
\text { pedias, libros de arte, etc) }\end{array}$} \\
\hline Librero & $\begin{array}{l}\text { Escritorio, } \\
\text { mesa }\end{array}$ & \multicolumn{4}{|c|}{$\begin{array}{l}\text { Espacio privado para estudiar y/o realizar tus } \\
\text { tareas }\end{array}$} \\
\hline
\end{tabular}

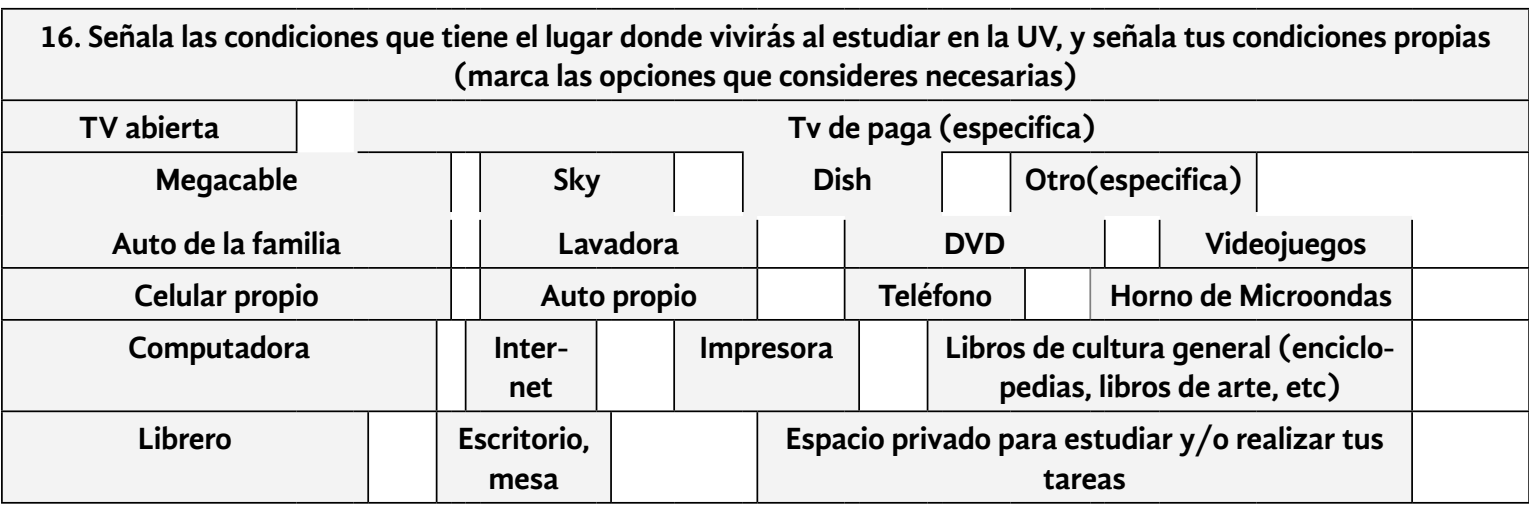

17. Los recursos económicos con que cuentas para desarrollar tus actividades académicas son: (señala únicamente una opción)

\begin{tabular}{|c|c|c|c|c|c|c|c|c|}
\hline Muy buenos & Buenos & & Regulares & \multicolumn{3}{|c|}{ Malos } & \\
\hline
\end{tabular}


19. Antes de ingresar a la UV habías intentado ingresar a otra institución de educación superior (universidad, instituto, Normal, etc,) con un resultado no favorable:

\begin{tabular}{|c|l|l|l|l|l|} 
Sí & & Señala cuál y en qué año & & No & \\
\hline
\end{tabular}

20. Habías estudiado en otra institución de educación superior (universidad, instituto, Normal, etc), antes de ingresar a la UV:

\begin{tabular}{|l|l|l|l|l|l|}
\hline Sí & \multicolumn{2}{|c|}{$\begin{array}{c}\text { Nombre de } \\
\text { la institu- } \\
\text { ción }\end{array}$} & En qué año & \\
\hline \multicolumn{2}{|l|}{} \\
\hline \multicolumn{2}{|c|}{ Nombre de la carrera } & & No & \\
\hline
\end{tabular}

\begin{tabular}{|c|c|c|c|c|c|}
\hline \multicolumn{7}{|c|}{ 21. Habías intentado ingresar anteriormente a la UV con un resultado no favorable: } \\
\hline Sí & & Cuántas veces & En que año (s) & & No \\
\hline \multicolumn{3}{|c|}{ A cuál o cuáles carreras } & & & No \\
\hline
\end{tabular}

\begin{tabular}{|c|c|c|c|c|}
\hline \multicolumn{6}{|c|}{ 22. Habías estudiado en otra carrera de la UV antes de ingresar a esta carrera: } \\
\hline Sí & Cuál & & En que año & \\
\hline Cuantos años cursaste de esa carrera & & No & \\
\hline
\end{tabular}

23. La carrera que cursas actualmente, fue tu primera opción este año en la UV:

\begin{tabular}{|l|l|l|l|l|l|} 
Sí & & No & & Cuál o cuáles carreras elegiste primero & \\
\hline
\end{tabular}

24. Cuál es el promedio que obtuviste en el bachillerato:

25. Qué lugar ocupan tus estudios dentro de las prioridades de tu familia (señala únicamente una opción)

\begin{tabular}{|l|l|l|l|l|l|l|l|}
\hline Muy alto & Alto & & Medio & & Bajo & & Muy bajo \\
\hline
\end{tabular}

26. Tienes pensado estudiar la carrera completa (señala únicamente una opción)

\begin{tabular}{|l|l|l|l|l|l|l} 
Sí & & Solo hasta el primer año y me cambio de carrera & & No lo sé & & No \\
\hline
\end{tabular}

27. Una vez concluidos tus estudios de licenciatura, cómo consideras tus posibilidades de encontrar trabajo relacionado con tu profesión (Marca solo una opción)

\begin{tabular}{l|l|l|l|l|l|l} 
Altas & & Medias & & Bajas & & Nulas \\
\hline
\end{tabular}

28. De acuerdo con la carrera que cursas, en qué espacio laboral pretenderías preferentemente desarrollar tu actividad profesional (señala las opciones que consideres necesarias)

\begin{tabular}{|c|c|c|c|c|c|c|}
\hline $\begin{array}{c}\text { En una institución } \\
\text { educativa }\end{array}$ & En el sector público & En una empresa privada & $\begin{array}{c}\text { En el negocio de } \\
\text { mi familia }\end{array}$ & \\
\hline En un negocio propio & $\begin{array}{c}\text { En el libre ejercicio de } \\
\text { la profesión }\end{array}$ & Otra, especifica & \\
\hline
\end{tabular}

29. En comparación con la ocupación de tu padre, madre o de la persona que ocupa el lugar de jefe de familia cómo percibes el desarrollo de tu vida profesional una vez que concluyas tus estudios de licenciatura (señala una opción por cada renglón)

\begin{tabular}{|c|c|c|c|c|}
\hline $\begin{array}{l}\text { Valoración de la carrera } \\
\text { Percepción de ocupación }\end{array}$ & Inferior & Igual & Mejor & Considerablemente mejor \\
\hline En términos económicos & & & & \\
\hline En cuanto al prestigio social & & & & \\
\hline
\end{tabular}


30. Dentro de tus planes futuros, piensas realizar estudios de posgrado Sí No Aún no lo se

31. De acuerdo con tu trayectoria en el bachillerato, cuál es la frecuencia con la que realizabas las siguientes actividades (asigna una frecuencia por cada actividad)

\begin{tabular}{|c|l|l|l|l|}
\hline $\begin{array}{c}\text { Frecuencia } \\
\text { Actividad }\end{array}$ & Siempre & $\begin{array}{c}\text { Con alguna fre- } \\
\text { cuencia }\end{array}$ & A veces & Nunca \\
\hline Asistir a clases & & & & \\
\hline Asistir puntualmente a clases & & & & \\
\hline Escuchar a los maestros & & & & \\
\hline Realizar preguntas en clase & & & & \\
\hline Realizar trabajos & & & & \\
\hline Realizar lecturas de la clase & & & & \\
\hline $\begin{array}{c}\text { Discutir los puntos de vista del } \\
\text { maestro }\end{array}$ & & & & \\
\hline Lectura previa a la clase & & & & \\
\hline
\end{tabular}

32. De acuerdo con tu trayectoria en el bachillerato, cuál es la frecuencia con la que tus profesores realizaban las siguientes actividades (asigna una frecuencia por cada actividad)

\begin{tabular}{|c|l|l|l|l|}
\hline $\begin{array}{c}\text { Frecuencia } \\
\text { Actividad }\end{array}$ & Siempre & $\begin{array}{c}\text { Con alguna fre- } \\
\text { cuencia }\end{array}$ & A veces & Nunca \\
\hline $\begin{array}{c}\text { Dejaban en claro los objetivos del } \\
\text { curso }\end{array}$ & & & & \\
\hline Los maestros dictaban & & & & \\
\hline Se realizaban dinámicas de grupo & & & & \\
\hline Exponían los alumnos & & & & \\
\hline $\begin{array}{c}\text { Los maestros hacían preguntas } \\
\text { sobre las lecturas }\end{array}$ & & & & \\
\hline $\begin{array}{c}\text { Los maestros realizaban lectura en } \\
\text { clase }\end{array}$ & & & & \\
\hline Exponían los maestros & & & & \\
\hline
\end{tabular}

33. De acuerdo con tu experiencia en el bachillerato, en promedio, cuántas horas a la semana dedicabas a la programación de tus clases y/o trabajos escolares: (Marca una opción por cada renglón)

\begin{tabular}{|c|c|c|c|c|c|c|}
\hline & $\begin{array}{c}\text { Menos de una } \\
\text { hora }\end{array}$ & $1-5 \mathrm{hrs}$ & $6-10$ & $11-15$ & $16-20$ & Más de $20 \mathrm{hrs}$ \\
\hline $\begin{array}{c}\text { En términos de } \\
\text { lecturas }\end{array}$ & & & & & & \\
\hline $\begin{array}{c}\text { Realización de } \\
\text { trabajos y tareas }\end{array}$ & & & & & & \\
\hline
\end{tabular}

34. En los años que estudiaste en el bachillerato ¿con quién vivías? (marca únicamente una opción)

Con ambos padres $\quad$ Con ambos padres y hermanos
Sólo con mi padre

Sólo con mi madre 


\begin{tabular}{|c|c|c|c|}
\hline $\begin{array}{l}\text { Con mi padre y } \\
\text { hermanos }\end{array}$ & Con mi madre y hermanos & $\begin{array}{c}\text { Con mi esposo (a) } \\
\text { o pareja }\end{array}$ & $\begin{array}{c}\text { Con mi } \\
\text { esposo (a) } \\
\text { o pareja e } \\
\text { hijos }\end{array}$ \\
\hline Con amigos & Con pupilos & \multicolumn{2}{|c|}{ Con otros familiares } \\
\hline \multicolumn{4}{|l|}{ Otros, especifica } \\
\hline \multicolumn{4}{|c|}{ 35. Con quién vivirás ahora que ingresaste a la UV (marca únicamente una opción) } \\
\hline Con ambos padres & $\begin{array}{l}\text { Con ambos padres y her- } \\
\text { manos }\end{array}$ & Solo con mi padre & Solo con mi madre \\
\hline $\begin{array}{c}\text { Con mi padre y } \\
\text { hermanos }\end{array}$ & Con mi madre y hermanos & $\begin{array}{c}\text { Con mi esposo (a) } \\
\text { o pareja }\end{array}$ & $\begin{array}{c}\text { Con mi esposo (a) o } \\
\text { pareja e hijos }\end{array}$ \\
\hline Con amigos & Con pupilos & \multicolumn{2}{|c|}{ Con otros familiares } \\
\hline Otros, especifica & & & \\
\hline
\end{tabular}

36. De acuerdo con tu experiencia en el bachillerato, con qué frecuencia acostumbrabas estudiar y/o realizar trabajos escolares con tus compañeros de clase (Marca únicamente una opción)

\begin{tabular}{|c|l|l|l|l|l|l|l|}
\hline Siempre & & Con alguna frecuencia & & A veces & & Nunca & \\
\hline
\end{tabular}

37. En un cálculo general señala cuántos amigos cercanos tenías en los años en que estudiabas el bachillerato (señala un número por cada opción)

\begin{tabular}{|l|l|l} 
Número de amigos dentro de tu escuela & & Número de amigos fuera de tu escuela
\end{tabular}

38. En un cálculo general, señala la frecuencia con la que participabas en estas agrupaciones, en los años en que estudiabas en el bachillerato (asigna una frecuencia en cada agrupación)

\begin{tabular}{|c|c|c|c|c|}
\hline Frecuencia & $\begin{array}{c}\text { Siempre } \\
\text { (número de } \\
\text { horas por } \\
\text { semana) }\end{array}$ & $\begin{array}{c}\text { Con alguna fre- } \\
\text { cuencia } \\
\text { (número de horas } \\
\text { por semana) }\end{array}$ & $\begin{array}{c}\text { A veces } \\
\text { (número de } \\
\text { horas por } \\
\text { semana) }\end{array}$ & $\begin{array}{c}\text { Nunca } \\
\text { (número de horas } \\
\text { por semana) }\end{array}$ \\
\hline Dentro de tu escuela & & & & \\
\hline Banda de guerra & & & & \\
\hline Deportiva & & & & \\
\hline Artística/cultural & & & & \\
\hline De estudio y tareas & & & & \\
\hline $\begin{array}{c}\text { De protesta social (manifestacio- } \\
\text { nes, plantones, marchas, etc) }\end{array}$ & & & & \\
\hline Otras, especifica & & & & \\
\hline Fuera de tu escuela & & & & \\
\hline Política & & & & \\
\hline Religiosa & & & & \\
\hline Artística/cultural & & & & \\
\hline Deportiva & & & & \\
\hline Destras, especifica & & & & \\
\hline
\end{tabular}

39. Cuántos de tus amigos del bachillerato cursarán una carrera en la UV: (señala un número por cada opción) 


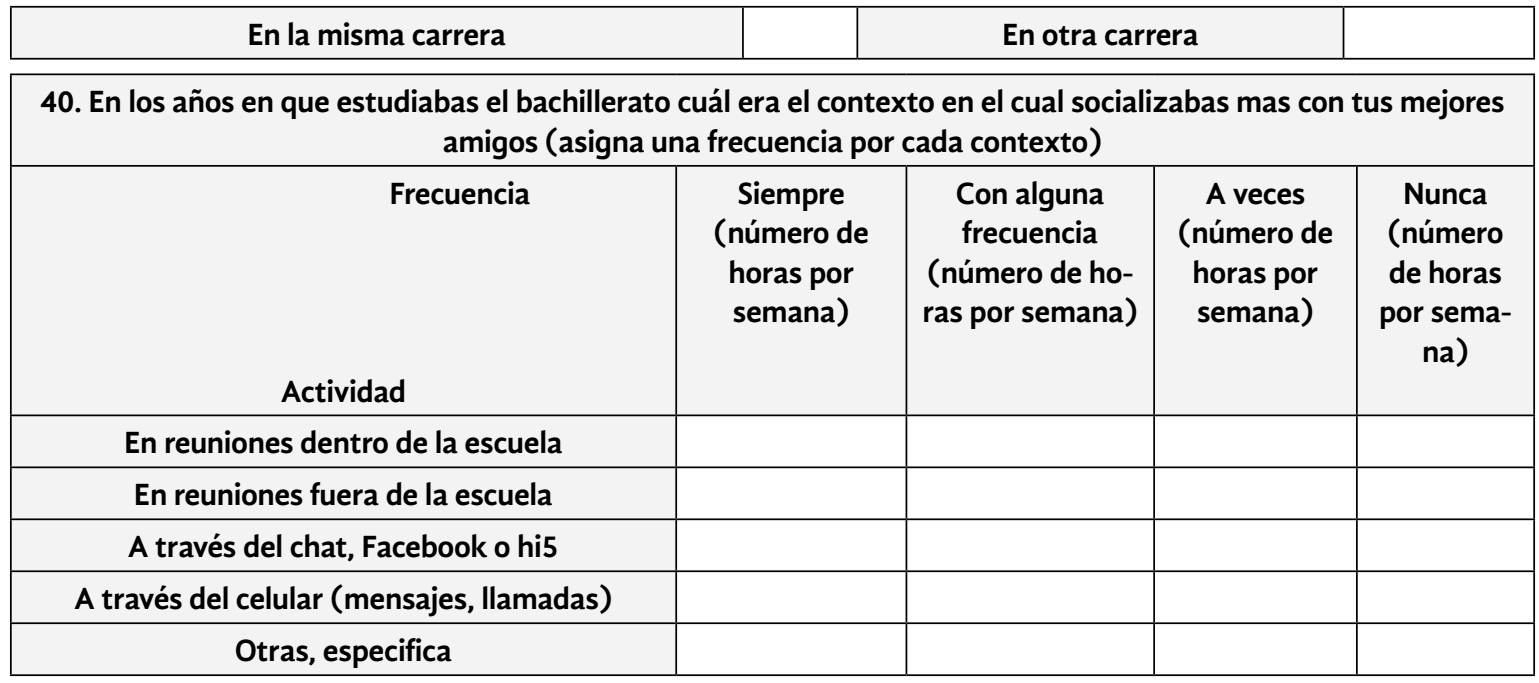

41. ¿Por qué decidiste estudiar la carrera en la que te encuentras? (por cada opción marca el nivel de importancia en la decisión de estudiar la carrera)

\begin{tabular}{|c|l|l|l|}
\hline $\begin{array}{c}\text { Nivel de importancia } \\
\text { Opciones }\end{array}$ & Muy alto & Considerable & Nulo \\
\hline Por sugerencia de mis padres o tutores & & & \\
\hline Por sugerencia de mis amigos & & & \\
\hline Por sugerencia de otro familiar & & & \\
\hline Por convicción personal & & & \\
\hline Por sugerencia de los maestros del bachillerato & & & \\
\hline Por sugerencia de mi novio (a) & & & \\
\hline Por mis posibilidades o las de mi familia de financiar mi carrera & & & \\
\hline Por el nivel de ingresos que puede darme esta profesión & & & \\
\hline Otra, especifica & & & \\
\hline
\end{tabular}

42. Con qué frecuencia interactuabas con tus profesores del bachillerato, (asigna una frecuencia en cada agrupación)

\begin{tabular}{|c|c|c|c|c|}
\hline Frecuencia & Siempre & $\begin{array}{c}\text { Con alguna fre- } \\
\text { cuencia }\end{array}$ & A veces & Nunca \\
\hline Apoyos & & & & \\
\hline En el contexto de la clase & & & & \\
\hline Fuera del contexto de la clase & & & & \\
\hline
\end{tabular}

43. Fuera del contexto de la clase, ¿qué tipo de temáticas y situaciones propiciaban la interacción con tus profesores?

(Asigna una frecuencia por cada uno de los siguientes eventos)

\begin{tabular}{|c|c|c|c|c|}
\hline Frecuencia & $\begin{array}{c}\text { Siempre } \\
\text { (número de horas } \\
\text { por semana) }\end{array}$ & $\begin{array}{c}\text { Con alguna } \\
\text { frecuencia } \\
\text { (número de } \\
\text { horas por } \\
\text { semana) }\end{array}$ & $\begin{array}{c}\text { A veces } \\
\text { (número de } \\
\text { horas por } \\
\text { semana) }\end{array}$ & $\begin{array}{c}\text { Nunca } \\
\text { (número de horas } \\
\text { por semana) }\end{array}$ \\
\hline Actividad & & & \\
\hline
\end{tabular}




\begin{tabular}{|c|l|l|l|l|}
\hline Eventos culturales & & & & \\
\hline Eventos sociales & & & & \\
\hline Eventos académicos & & & & \\
\hline $\begin{array}{c}\text { Apoyos académicos (tutorías, otros } \\
\text { apoyos) }\end{array}$ & & & & \\
\hline
\end{tabular}

44. En los años en que estudiaste el bachillerato ¿con qué frecuencia viviste las siguientes situaciones? (Marca una frecuencia por cada situación)

\begin{tabular}{|c|c|c|c|c|}
\hline $\begin{array}{l}\text { Frecuenci } \\
\text { Situación }\end{array}$ & Siempre & $\begin{array}{l}\text { Con alguna } \\
\text { frecuencia }\end{array}$ & A veces & Nunca \\
\hline \multicolumn{5}{|c|}{ Fui reportado por mis profesores } \\
\hline \multicolumn{5}{|l|}{ Fui expulsado de la escuela } \\
\hline \multicolumn{5}{|c|}{$\begin{array}{l}\text { Fui invitado a algún evento especial (deportivo, cultural, } \\
\qquad \text { artístico, etc) }\end{array}$} \\
\hline \multicolumn{5}{|l|}{ Gané algún tipo de concurso } \\
\hline \multicolumn{5}{|c|}{ Me resultaba indiferente participar en algo } \\
\hline Otros eventos, especifica & & & & \\
\hline
\end{tabular}

45. En los años en los que estudiaste el bachillerato, con qué frecuencia asististe a los siguientes eventos (asigna una frecuencia por cada evento)

\begin{tabular}{|c|l|l|l|l|}
\hline Frecuencia & Siempre & $\begin{array}{c}\text { Con alguna } \\
\text { frecuencia }\end{array}$ & A veces & Nunca \\
\hline Música clásica & & & & \\
\hline Conciertos de rock, salsa, grupera, reggaetón, etc & & & & \\
\hline Exposiciones artísticas & & & & \\
\hline Fiestas del pueblo o barrio & & & & \\
\hline Cine & & & & \\
\hline Danza & & & & \\
\hline Eventos deportivos & & & & \\
\hline Teatro & & & & \\
\hline Museos & & & & \\
\hline Otro, especifica & & & & \\
\hline
\end{tabular}

46. En los años en los que estudiaste el bachillerato, en promedio cuántas horas veías televisión y/o dvd's (películas, videos, videojuegos, etc) (marca una opción por cada renglón)

\begin{tabular}{|c|c|c|c|c|}
\hline & No veía & De 1 a 5 hrs. & De 6 a 10 hrs. & Más de 10 hrs. \\
\hline A la semana & & & & \\
\hline En fin de semana & & & & \\
\hline
\end{tabular}

Gracias por tu colaboración

Xalapa, Veracruz, Agosto de 2011 
Encuesta para estudiantes de tercer semestre

Estimado estudiante, esta encuesta fue diseñada para conocer las prácticas sociales, culturales y académicas de los estudiantes de la Universidad Veracruzana. Te suplicamos leas detenidamente las instrucciones y contestes las preguntas con información real.

Nombre:

Matrícula:

Facultad:

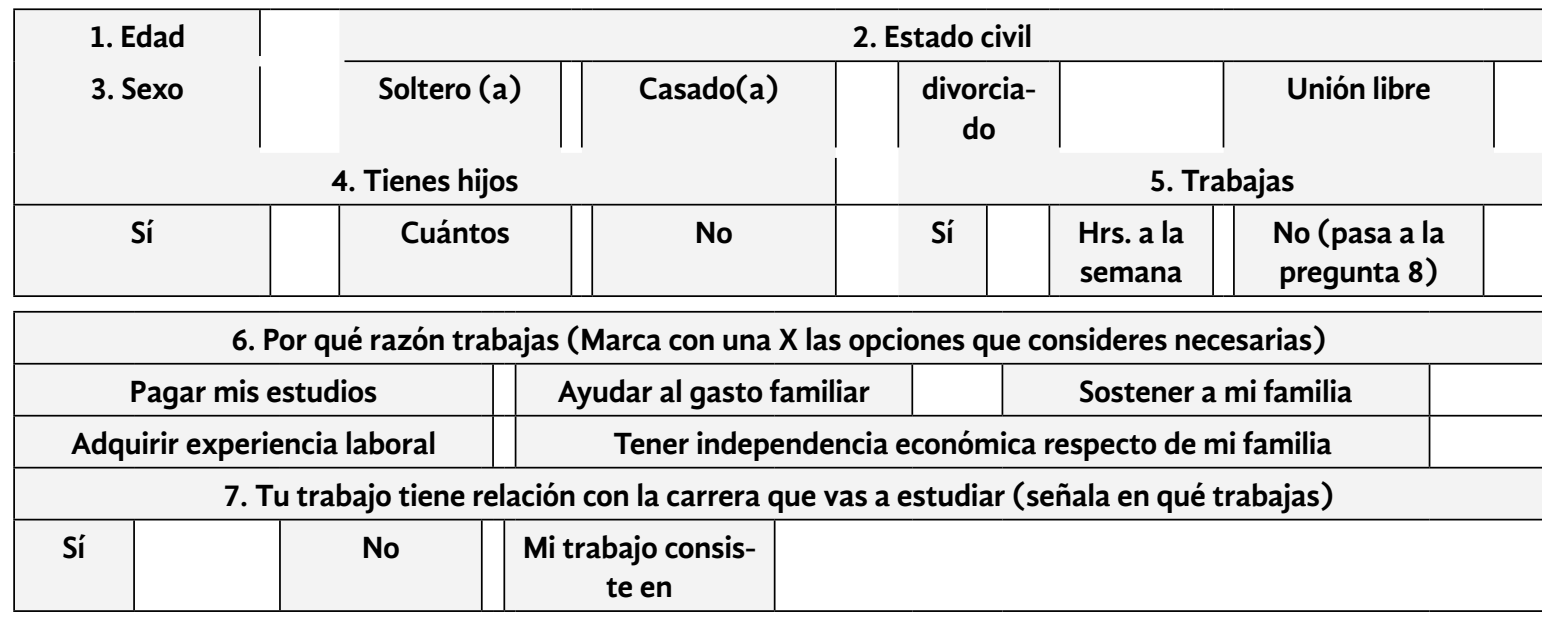

\begin{tabular}{|c|c|c|c|c|c|c|c|}
\hline \multicolumn{7}{|c|}{ 8. Actualmente, quien se encarga de la economía de tu casa } \\
\hline Padre o tutor & Madre o tutora & & $\begin{array}{c}\text { Padre y madre o tutor } \\
\text { y tutora }\end{array}$ & \multicolumn{2}{|c|}{ Yo me encargo } & \\
\hline Hermanos & & Otros familiares & & Todos contribuimos & & Otros, especifica & \\
\hline
\end{tabular}

9. Señala las condiciones que tiene el lugar donde vives actualmente (marca las opciones que consideres necesarias)

\begin{tabular}{|c|c|c|c|c|c|c|}
\hline TV abierta & \multicolumn{6}{|c|}{ Tv de paga (especifica) } \\
\hline Megacable & \multicolumn{2}{|c|}{ Sky } & Dis & & Otro(especifica) & \\
\hline Auto de la familia & \multicolumn{3}{|c|}{ Lavadora } & DVD & \multicolumn{2}{|c|}{ Videojuegos } \\
\hline Celular propio & \multicolumn{2}{|c|}{ Auto propio } & & Teléfono & \multicolumn{2}{|c|}{ Horno de Microondas } \\
\hline Computadora & Internet & & sora & \multicolumn{3}{|c|}{$\begin{array}{l}\text { Libros de cultura general (enciclo- } \\
\text { pedias, libros de arte, etc) }\end{array}$} \\
\hline Librero & $\begin{array}{l}\text { Escritorio, } \\
\text { mesa }\end{array}$ & & \multicolumn{4}{|c|}{$\begin{array}{c}\text { Espacio privado para estudiar y/o realizar tus } \\
\text { tareas }\end{array}$} \\
\hline
\end{tabular}

10. Después de un año en la UV, los recursos económicos con que cuentas para desarrollar tus actividades académicas son: (señala únicamente una opción)

\begin{tabular}{|c|c|c|c|c|}
\hline Muy buenos & Buenos & Regulares & \multicolumn{2}{|c|}{ Malos } \\
\hline \multicolumn{3}{|c|}{ 11. Tienes asignada la beca Pronabes } & Sí & No \\
\hline \multicolumn{4}{|c|}{ 12. Cuál es el promedio que tienes en los dos semestres cursados en la UV: } & \\
\hline
\end{tabular}


13. Después de un año en la UV ¿cuántos créditos has cursado?:

14. Después de un año en la Uv indica cuáles experiencias educativas del AFBG has cursado (señala una opción por cada renglón)

\begin{tabular}{|c|c|c|}
\hline Experiencias educativas & Sí & No \\
\hline \multicolumn{3}{|l|}{ Inglés I } \\
\hline \multicolumn{3}{|l|}{ Inglés II } \\
\hline \multicolumn{3}{|c|}{ Taller de Lectura y Redacción a través del mundo contemporáneo } \\
\hline \multicolumn{3}{|c|}{ Habilidades del pensamiento crítico y creativo } \\
\hline Computación Básica & & \\
\hline
\end{tabular}

\begin{tabular}{|c|c|c|c|c|c|}
\hline \multicolumn{6}{|c|}{ 15. Qué lugar ocupan tus estudios dentro de las prioridades de tu familia (señala solo una opción) } \\
\hline Muy alto & Alto & Medio & Bajo & Muy & \\
\hline \multicolumn{6}{|c|}{ 16. Tienes pensado estudiar la carrera completa (señala únicamente una opción) } \\
\hline Sí & Solo hast & año y $\mathrm{m}$ & carrera & No lo sé & No \\
\hline
\end{tabular}

17. Cuando concluyas la licenciatura, cómo consideras tus posibilidades de encontrar trabajo relacionado con tu profesión (Marca solo una opción)

\begin{tabular}{|c|c|c|c|c|c|c|c|}
\hline Altas & & Medias & & Bajas & Nulas & \\
\hline
\end{tabular}

18. De acuerdo con la carrera que cursas, en qué espacio laboral pretenderías preferentemente desarrollar tu actividad profesional (señala las opciones que consideres necesarias)

\begin{tabular}{|c|c|c|c|c|c|}
\hline En una institución educativa & & $\begin{array}{c}\text { En el } \\
\text { sector } \\
\text { público }\end{array}$ & $\begin{array}{c}\text { En una } \\
\text { empresa } \\
\text { privada }\end{array}$ & $\begin{array}{c}\text { En el } \\
\text { negocio } \\
\text { de mi } \\
\text { familia }\end{array}$ & \\
\hline En un negocio propio & \multicolumn{2}{|c|}{$\begin{array}{c}\text { En el libre } \\
\text { ejercicio de la } \\
\text { profesión }\end{array}$} & $\begin{array}{c}\text { Otra, } \\
\text { especifica }\end{array}$ & \\
\hline
\end{tabular}

19. En comparación con la ocupación de tu padre, madre o quien ocupe el lugar de jefe de familia cómo percibes el desarrollo de tu vida profesional una vez que concluyas tus estudios de licenciatura (señala una opción por cada renglón)

\begin{tabular}{|c|l|l|l|l|}
\hline Valoración de la carrera & Inferior & Igual & Mejor & Considerablemente mejor \\
\hline Percepción de ocupación & & & & \\
\hline En términos económicos & & & & \\
\hline En cuanto al prestigio social & & & \\
\hline
\end{tabular}

20. Dentro de tus planes futuros, piensas realizar estudios de posgrado

\begin{tabular}{l|l|l|l|l} 
Sí & No & & Aún no lo se \\
\hline
\end{tabular}

21. Después de un año en la UV, en qué grado consideras satisfechas las expectativas que tenías al ingresar a la carrera? (Marca solo una opción)

\begin{tabular}{l|l|l|l|l|l|l} 
Altas & & Medias & & Bajas & & Nulas \\
\hline
\end{tabular}

22. Después de un año en la UV, ¿recomendarías a un amigo o pariente estudiar en la UV?(Marca solo una opción)

Sí No 
23. Si hoy tuvieras que decidir dónde estudiar ¿lo harías de nuevo en la UV? (Marca solo una opción)

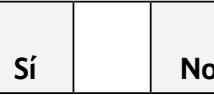

24. En general ¿Cómo calificas el desempeño de los profesores? (Marca solo una opción)

\begin{tabular}{|c|c|c|c|c|c|c|}
\hline \multicolumn{6}{|c|}{ 24. En general ¿Cómo calificas el desempeño de los profesores? (Marca solo una opción) } \\
\hline Muy bueno & & Bueno & & Regular & & Malo \\
\hline
\end{tabular}

25. Con qué frecuencias realizas estas actividades (asigna una frecuencia por cada actividad)

\begin{tabular}{|c|l|l|l|l|}
\hline \multicolumn{2}{|c|}{ 25. Con qué frecuencias realizas estas actividades (asigna una frecuencia por cada actividad) } \\
\hline $\begin{array}{c}\text { Frecuencia } \\
\text { Actividad }\end{array}$ & Siempre & $\begin{array}{c}\text { Con alguna } \\
\text { frecuencia }\end{array}$ & A veces & Nunca \\
\hline Asistir a clases & & & & \\
\hline Asistir puntualmente a clases & & & & \\
\hline Escuchar a los maestros & & & & \\
\hline Realizar preguntas en clase & & & & \\
\hline Realizar trabajos & & & & \\
\hline Realizar lecturas de la clase & & & & \\
\hline Discutir los puntos de vista del maestro & & & & \\
\hline Lectura previa a la clase & & & & \\
\hline
\end{tabular}

26. Después de un año en la UV, cuál es la frecuencia con la que tus profesores realizan las siguientes actividades (asigna una frecuencia por cada actividad)

\begin{tabular}{|c|l|l|l|l|}
\hline $\begin{array}{c}\text { Actividad } \\
\text { frecuencia }\end{array}$ & Siempre & $\begin{array}{c}\text { Con alguna fre- } \\
\text { cuencia }\end{array}$ & A veces & Nunca \\
\hline $\begin{array}{c}\text { Dejan en claro los objetivos del } \\
\text { curso maestros dictan }\end{array}$ & & & & \\
\hline Se realizan dinámicas de grupo & & & & \\
\hline Exponen los alumnos & & & & \\
\hline $\begin{array}{c}\text { Los maestros hacen preguntas } \\
\text { sobre las lecturas }\end{array}$ & & & & \\
\hline $\begin{array}{c}\text { Los maestros realizan lectura en } \\
\text { clase }\end{array}$ & & & & \\
\hline Exponen los maestros & & & & \\
\hline
\end{tabular}

27. Después de un año en la UV, en promedio, cuántas horas a la semana dedicas a la programación de tus clases y/o trabajos escolares: (Marca una opción por cada renglón)

\begin{tabular}{|c|l|l|l|l|l|c|}
\hline & Menos de una hora & $1-5 \mathrm{hrs}$ & $6-10$ & $11-15$ & $16-20$ & $\begin{array}{c}\text { Más de } \\
20 \mathrm{hrs}\end{array}$ \\
\hline En términos de lecturas & & & & & & \\
\hline $\begin{array}{c}\text { Realización de trabajos } \\
\mathrm{y} \text { tareas }\end{array}$ & & & & & & \\
\hline
\end{tabular}

\begin{tabular}{|c|c|c|c|}
\hline \multicolumn{2}{|c|}{ 28. Tienes asignado un tutor } & No (pasa a la pregunta 30) \\
\hline Sí & & Número de veces que te entrevistas con él & \\
\hline \multicolumn{5}{|c|}{ 29. Si tienes asignado un tutor cuántas veces te entrevistas con él en cada semestre } \\
\hline Sí & & . & \\
\hline
\end{tabular}




\section{Consideras que para ti es necesario asistir a las tutorías para comprender mejor los contenidos que estudias en tu carrera}

Sí

No

31. Durante tu primer año de estudios ¿has tenido alguna experiencia personal fuera de la UV relacionada con tu futura profesión: asistente de algún profesor o u otras actividades similares? (Marca solo una opción)

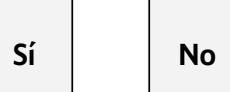

32. En el primer año de tu carrera ¿existen las siguientes prácticas? (señala una opción por cada renglón)

\begin{tabular}{|c|c|c|}
\hline Prácticas & Sí & No \\
\hline Prácticas de servicio a la comunidad & & \\
\hline Asistencia a conferencias académicas & & \\
\hline Visitas a museos & & \\
\hline Visitas a escuelas u otras instituciones académicas & & \\
\hline Otras, especifica & & \\
\hline
\end{tabular}

33. En los años en que estudiabas el bachillerato, ¿con qué frecuencia asistías a eventos académicos?

\begin{tabular}{l|l|l|l|l|l|l} 
Siempre & & Con alguna frecuencia & & A veces & & Nunca \\
\hline
\end{tabular}

34. Después de un año en la UV, con qué frecuencia has asistido a eventos académicos dentro de la Universidad Veracruzana

\begin{tabular}{l|l|l|l|l|l|l|} 
Siempre & & Con alguna frecuencia & & A veces & & Nunca
\end{tabular}

35. Con qué frecuencia has asistido a eventos académicos fuera de la Universidad Veracruzana Siempre Con alguna frecuencia A veces Nunca

36. Después de un año en la UV, señala el número de amigos que en general tienes dentro de la escuela

37. Después de un año en la UV, señala cuántas personas consideras que son tus mejores amigos dentro de la escuela

38. Después de un año en la UV con qué frecuencia acostumbrabas estudiar y/o realizar trabajos escolares con tus compañeros de clase (Marca únicamente una opción)

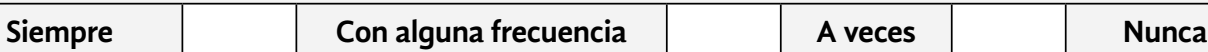

39. Después de un año en la UV, señala la frecuencia con la que participas en las siguientes agrupaciones, (asigna una frecuencia en cada agrupación)

\begin{tabular}{|c|l|l|l|l|}
\hline Frecuencia & $\begin{array}{c}\text { Siempre } \\
\text { (número de horas } \\
\text { por semana) }\end{array}$ & $\begin{array}{c}\text { Con alguna fre- } \\
\text { cuencia } \\
\text { (número de horas } \\
\text { por semana) }\end{array}$ & $\begin{array}{c}\text { A veces } \\
\text { (número } \\
\text { de horas } \\
\text { por sema- } \\
\text { na) }\end{array}$ & $\begin{array}{c}\text { Nunca } \\
\text { (número de horas } \\
\text { por semana) }\end{array}$ \\
\hline Empresarial & & & & \\
\hline Deportiva & & & & \\
\hline Artística/cultural & & & & \\
\hline De estudio y tareas & & & & \\
\hline Representación estudiantil & & & & \\
\hline De servicio a la comunidad & & & & \\
\hline
\end{tabular}




\begin{tabular}{|c|l|l|l|l|}
\hline Política & & & & \\
\hline $\begin{array}{c}\text { De protesta social (manifestacio- } \\
\text { nes, plantones, marchas, etc) }\end{array}$ & & & & \\
\hline Otras, especifica & & & & \\
\hline
\end{tabular}

40. Después de un año en la UV, con qué frecuencia interactúas con tus profesores dentro de la facultad (asigna una frecuencia en cada agrupación)

\begin{tabular}{|c|l|l|l|l|l|l|}
\hline Siempre & & Con alguna frecuencia & & A veces & & Nunca \\
\hline
\end{tabular}

41. Fuera del contexto de la clase, pero dentro de la escuela ¿qué tipo de temáticas y situaciones propician la interacción con tus profesores? (Asigna una frecuencia por cada uno de los siguientes eventos)

\begin{tabular}{|c|l|l|l|l|}
\hline Frecuencia & $\begin{array}{c}\text { Siempre } \\
\text { (número de horas por } \\
\text { semana) }\end{array}$ & $\begin{array}{c}\text { Con alguna } \\
\text { Frecuencia } \\
\text { (número de horas } \\
\text { por semana) }\end{array}$ & $\begin{array}{c}\text { A veces } \\
\text { (número } \\
\text { de horas } \\
\text { por sema- } \\
\text { na) }\end{array}$ & $\begin{array}{c}\text { Nunca } \\
\text { (número de } \\
\text { horas por } \\
\text { semana) }\end{array}$ \\
\hline Eventos deportivos & & & \\
\hline Eventos culturales & & & \\
\hline Eventos sociales & & & \\
\hline Eventos académicos & & & \\
\hline $\begin{array}{c}\text { Apoyos académicos (tutorías, otros } \\
\text { apoyos) }\end{array}$ & & & & \\
\hline $\begin{array}{c}\text { De protesta social (manifestaciones, } \\
\text { plantones, marchas, etc) }\end{array}$ & & & & \\
\hline Fiesta/Antros & & & \\
\hline Otras, especifica & & & \\
\hline 42. Después de un año en la UV, cuántos amigos tienes en general fuera de la escuela \\
\hline 43. Después de un año en la UV, cuántos son tus mejores amigos fuera de la escuela \\
\hline
\end{tabular}

44. Después de un año en la UV, señala la frecuencia con la que participas en las siguientes agrupaciones fuera de la escuela, (asigna una frecuencia en cada agrupación)

\begin{tabular}{|c|l|l|l|l|}
\hline Frecuencia & $\begin{array}{c}\text { Siempre } \\
\text { (número de horas } \\
\text { por semana) }\end{array}$ & $\begin{array}{c}\text { Con alguna fre- } \\
\text { cuencia } \\
\text { (número de horas } \\
\text { por semana) }\end{array}$ & $\begin{array}{c}\text { A veces } \\
\text { (número de } \\
\text { horas por } \\
\text { semana) }\end{array}$ & $\begin{array}{c}\text { Nunca(número } \\
\text { de horas por } \\
\text { semana) }\end{array}$ \\
\hline Empresarial & & & & \\
\hline Deportiva & & & & \\
\hline Artística/cultural & & & & \\
\hline De estudio y tareas & & & & \\
\hline Representación estudiantil & & & & \\
\hline De servicio a la comunidad & & & & \\
\hline Religiosa & & & & \\
\hline Política & & & & \\
\hline
\end{tabular}




\begin{tabular}{|c|l|l|l|l|}
\hline $\begin{array}{c}\text { De protesta social (manifestacio- } \\
\text { nes, plantones, marchas, etc) }\end{array}$ & & & & \\
\hline Otras, especifica & & & & \\
\hline
\end{tabular}

45. Después de un año en la UV, con qué frecuencia interactúas con tus profesores fuera de la facultad (asigna una frecuencia en cada agrupación)

\begin{tabular}{l|l|l|l} 
Con alguna frecuencia & & A veces \\
\hline
\end{tabular}

\begin{tabular}{|c|c|c|c|c|}
\hline \multicolumn{2}{|c|}{ 46. Fuera de la escuela ¿qué tipo de temáticas y situaciones propician la interacción con tus profesores? (Asigna } \\
una frecuencia por cada uno de los siguientes eventos) \\
Actividad & $\begin{array}{c}\text { Siempre } \\
\text { (número de } \\
\text { horas por } \\
\text { semana) }\end{array}$ & $\begin{array}{c}\text { Con alguna } \\
\text { Frecuencia } \\
\text { (número de ho- } \\
\text { ras por semana) }\end{array}$ & $\begin{array}{c}\text { A veces } \\
\text { (número } \\
\text { de horas } \\
\text { por sema- } \\
\text { na) }\end{array}$ & $\begin{array}{c}\text { Nunca } \\
\text { (número de } \\
\text { horas por } \\
\text { semana) }\end{array}$ \\
\hline Eventos deportivos & & & & \\
\hline Eventos culturales & & & & \\
\hline Eventos sociales & & & & \\
\hline Eventos académicos & & & & \\
\hline Apoyos académicos (tutorías, otros apoyos) & & & & \\
\hline Fiesta/Antros & & & & \\
\hline De protesta social (manifestaciones, plantones, \\
marchas, etc)
\end{tabular}

47. Si consideras que tu presencia en actividades políticas o de protesta social fue importante, señala la frecuencia y el grado de relevancia de tu participación en agrupaciones y actividades de este tipo

\begin{tabular}{|c|c|c|}
\hline $\begin{array}{l}\text { Frecuencia } \\
\text { Actividad }\end{array}$ & $\begin{array}{l}\text { Participación con cierta frecuen- } \\
\text { cia }\end{array}$ & $\begin{array}{c}\text { Participación en forma } \\
\text { relevante }\end{array}$ \\
\hline \multicolumn{3}{|l|}{ Dentro de la escuela } \\
\hline \multicolumn{3}{|l|}{ Formulando demandas específicas } \\
\hline \multicolumn{3}{|l|}{ Asistir a marchas } \\
\hline \multicolumn{3}{|l|}{ Asistir a plantones } \\
\hline \multicolumn{3}{|l|}{ Formar comisiones de protesta } \\
\hline \multicolumn{3}{|l|}{ Integrar grupos de protesta social } \\
\hline \multicolumn{3}{|l|}{$\begin{array}{l}\text { Ser consejero estudiantil o formar parte de la } \\
\text { consejería }\end{array}$} \\
\hline \multicolumn{3}{|l|}{ Otras, especifica } \\
\hline \multicolumn{3}{|l|}{ Fuera de la escuela } \\
\hline \multicolumn{3}{|l|}{ Formulando demandas específicas } \\
\hline \multicolumn{3}{|l|}{ Asistir a marchas } \\
\hline \multicolumn{3}{|l|}{ Asistir a plantones } \\
\hline \multicolumn{3}{|l|}{ Formar comisiones de protesta } \\
\hline \multicolumn{3}{|l|}{$\begin{array}{c}\text { Integrar grupos de protesta social externos a la } \\
\text { Universidad }\end{array}$} \\
\hline Otras, especifica & & \\
\hline
\end{tabular}




\begin{tabular}{|c|c|c|c|c|c|c|}
\hline \multicolumn{2}{|c|}{ 48. Después de un año en la UV, con quién vives actualmente (marca únicamente una opción) } \\
\hline $\begin{array}{c}\text { Con ambos } \\
\text { padres }\end{array}$ & Solo con mi padre & Solo con mi madre & Solo & \\
\hline Con amigos & & Con pupilos & & \multicolumn{2}{|c|}{ Con otros familiares } & \\
\hline
\end{tabular}

49. Después de un año en la UV, cuál es el contexto en el cual socializas más con tus mejores amigos (asigna una frecuencia por cada contexto)

\begin{tabular}{|c|c|c|c|c|}
\hline $\begin{array}{l}\text { Frecuencia } \\
\text { Actividad } \\
\end{array}$ & Siempre & $\begin{array}{l}\text { Con alguna } \\
\text { frecuencia }\end{array}$ & A veces & Nunca \\
\hline \multicolumn{5}{|l|}{ A través del chat, Facebook o hi5 } \\
\hline \multicolumn{5}{|l|}{ A través del celular (mensajes, llamadas) } \\
\hline \multicolumn{5}{|l|}{ Antros } \\
\hline \multicolumn{5}{|l|}{ Visitas a la playa } \\
\hline \multicolumn{5}{|l|}{ Futbol u otro deporte } \\
\hline \multicolumn{5}{|l|}{ Excursiones } \\
\hline \multicolumn{5}{|l|}{ Cine u otros espacios culturales } \\
\hline \multicolumn{5}{|l|}{ Billar } \\
\hline \multicolumn{5}{|l|}{ Día de campo } \\
\hline \multicolumn{5}{|l|}{ Visitas al parque } \\
\hline \multicolumn{5}{|l|}{ Fiestas en casas de amigos } \\
\hline \multicolumn{5}{|l|}{ En reuniones dentro de la escuela } \\
\hline \multicolumn{5}{|l|}{ En reuniones fuera de la escuela } \\
\hline Otras, especifica & & & & \\
\hline
\end{tabular}

50. En promedio cuántas horas ves televisión y/o dvd's (películas, videos, videojuegos, etc) (marca una opción por cada renglón)

\begin{tabular}{|c|c|c|c|c|}
\hline & No veo & De 1 a 5 hrs. & De 6 a 10 hrs. & Más de 10 hrs. \\
\hline A la semana & & & & \\
\hline En fin de semana & & & & \\
\hline
\end{tabular}

51. Después de un año en la UV, con qué frecuencia asistes o participas en los siguientes eventos dentro de la Universidad (asigna una frecuencia por cada evento)

\begin{tabular}{|c|l|l|l|l|}
\hline Frecuencia & Siempre & $\begin{array}{c}\text { Con alguna } \\
\text { frecuencia }\end{array}$ & A veces & Nunca \\
\hline Evento & & & & \\
\hline $\begin{array}{c}\text { Conciertos clásica } \\
\text { reggaetón u otros }\end{array}$ & & & & \\
\hline Exposiciones artísticas & & & & \\
\hline Fiestas del pueblo o barrio & & & & \\
\hline Cine & & & & \\
\hline Danza & & & & \\
\hline Eventos deportivos & & & & \\
\hline Teatro & & & & \\
\hline Museos & & & & \\
\hline
\end{tabular}


52. En los años en que estudiabas el bachillerato, con qué frecuencia asistías en el bachillerato a los siguientes eventos (asigna una frecuencia por cada evento)

\begin{tabular}{|c|l|l|l|l|}
\hline Frecuencia & Siempre & $\begin{array}{c}\text { Con alguna } \\
\text { frecuencia }\end{array}$ & A veces & Nunca \\
\hline Evento & & & & \\
\hline Música clásica & & & & \\
\hline $\begin{array}{c}\text { Conciertos de rock, salsa, grupera, } \\
\text { reggaetón u otros }\end{array}$ & & & & \\
\hline Exposiciones artísticas & & & & \\
\hline Fiestas del pueblo o barrio & & & & \\
\hline Cine & & & & \\
\hline Danza & & & & \\
\hline Eventos deportivos & & & & \\
\hline Museos & & & & \\
\hline
\end{tabular}

53. Después de un año en la Uv con qué frecuencia asistes a los siguientes eventos fuera de la Universidad Veracruzana (asigna una frecuencia por cada evento)

\begin{tabular}{|c|l|l|l|l|}
\hline $\begin{array}{c}\text { Frecuencia } \\
\text { Evento }\end{array}$ & Siempre & $\begin{array}{c}\text { Con alguna } \\
\text { frecuencia } \\
\text { veces }\end{array}$ & Nunca \\
\hline Música clásica & & & & \\
\hline $\begin{array}{c}\text { Conciertos de rock, salsa, } \\
\text { grupera, reggaetón u otros }\end{array}$ & & & & \\
\hline Exposiciones artísticas & & & & \\
\hline Fiestas del pueblo o barrio & & & & \\
\hline Cine & & & & \\
\hline Danza & & & & \\
\hline Eventos deportivos & & & & \\
\hline Teatro & & & & \\
\hline Museos & & & & \\
\hline
\end{tabular}

54. Indica los tipos de programación que prefieres de la televisión (señala las opciones que consideres necesarias)

\begin{tabular}{|c|c|c|c|c|c|c|}
\hline Reality Shows & $\begin{array}{c}\text { Emi- } \\
\text { siones } \\
\text { deporti- } \\
\text { vas }\end{array}$ & $\begin{array}{c}\text { Telenovelas } \\
\text { Dibujos } \\
\text { anima- } \\
\text { dos }\end{array}$ & $\begin{array}{c}\text { Doticie- } \\
\text { ros }\end{array}$ & & \\
\hline $\begin{array}{c}\text { Programas de } \\
\text { concurso }\end{array}$ & $\begin{array}{c}\text { Musica- } \\
\text { les }\end{array}$ & & Otro, especifica & Películas & & \\
\hline Series (Sitcoms) & & Otales & & \\
\hline
\end{tabular}


55. Enlista los nombres de tus cinco programas favoritos de televisión en orden de preferencia donde la letra a) es el que más te gusta y así sucesivamente

a)

b)

c)

d)

e)

56. Durante tu primer año en la Universidad, ¿Escuchas algún programa de radio?

\begin{tabular}{|c|l|l|l|}
\hline Sí & No (pasa a la pregunta 67) & \\
\hline ¿Cuál es? & \multicolumn{3}{l}{} \\
\hline
\end{tabular}

57. En promedio cuántas horas escuchas la radio (marca una opción por cada renglón)

\begin{tabular}{|c|c|c|c|c|}
\hline \multicolumn{6}{|c|}{ 57. En promedio cuántas horas escuchas la radio (marca una opción por cada renglón) } \\
\hline & No escucho & De 1 a 5 hrs. & De 6 a 10 hrs. & Más de 10 hrs. \\
\hline De lunes a viernes & & & & \\
\hline En fin de semana & & & & \\
\hline
\end{tabular}

\begin{tabular}{|c|c|c|c|c|}
\hline \multicolumn{5}{|c|}{ 58. Durante tu primer año en la Universidad ¿Lees algún periódico? } \\
\hline Sí & ¿Cuál? & & No & \\
\hline \multicolumn{5}{|c|}{ Aproximadamente con qué frecuencia lo lees } \\
\hline Diario & & Cada semana & Cada mes & Casi nunca \\
\hline
\end{tabular}

\begin{tabular}{|c|c|c|c|c|c|}
\hline \multicolumn{5}{|c|}{ 59. Durante tu primer año en la Universidad ¿Lees alguna revista? } \\
\hline Sí & & ¿Cuál? & No & \\
\hline
\end{tabular}

60. Durante tu primer año en la Universidad, en promedio cuántas horas pasas en el Internet (marca una opción por cada renglón)

\begin{tabular}{|c|c|c|c|c|}
\hline & No lo uso & De 1 a 5 hrs. & De 6 a 10 hrs. & Más de 10 hrs. \\
\hline De lunes a viernes & & & & \\
\hline En fin de semana & & & & \\
\hline
\end{tabular}

61. Enlista los nombres de tus cinco sitios de Internet favoritos en orden de frecuencia con la que los visitas donde la letra a) es el que más visitas y así sucesivamente

a)

b)

c)

d)

e)

62. Considerando que un estudiante universitario debe de estar informado sobre los eventos que suceden a diario en su país y en el mundo, cuál puede ser tu fuente principal de información (Marca solamente uno)

\begin{tabular}{|l|l|l|l|l|l|l|}
\hline La televisión & La radio & & Medio impreso & & Internet & \\
\hline Otro, especifica & \multicolumn{1}{|l}{} \\
\hline
\end{tabular}




\section{Anexo 2}

Guía inicial de preguntas para las entrevistas a estudiantes de la generación de ingreso en agosto 2011, área de Humanidades.

La siguiente serie de preguntas están orientadas al conocimiento de las prácticas sociales, culturales y de participación política en el primer año de estudios universitarios. El objetivo para la recuperación de la información es conocer cómo se construye la socialización política entre los estudiantes en la medida en que ellos participan en diversos procesos relacionados con la vida política universitaria.

1. Cuando ingresaste a la Universidad Veracruzana vivías en Xalapa o por primera vez entraste en contacto con la ciudad y con la institución.

2. Cómo describes tu proceso de integración a la escuela durante el primer año de estudios.

3. Según la encuesta que aplicamos, antes de ingresar a la Universidad Veracruzana habías participado en actividades culturales, sociales, políticas (protesta social, manifestaciones, entre otras); ¿podrías decirnos si esta participación se limitaba a la escuela o se extendía a otros ámbitos?

4. Según la encuesta que aplicamos, tu participación en actividades de socialización política en el primer año de estudios de la carrera fue relevante; ¿podrías decirnos si esta participación se limitaba a la escuela o se extendía a otros ámbitos?

5. ¿En dónde consideras que tuviste mayor participación en actividades de socialización política: dentro o fuera de la escuela? ¿Por qué?

6. ¿Cuáles fueron los eventos que identificas como aquellos que influyeron en tu disposición para participar en actividades de socialización política?

7. ¿Cuáles grupos identificas como aquellos que influyeron en tu disposición para participar en actividades de socialización política, y en qué medida estabas integrado (a) a ellos?.

8. ¿Consideras que el área de humanidades representa un espacio cuyas características promueven la participación en actividades de socialización política?

9. ¿Consideras que el hecho de ser estudiante universitario de humanidades te aporta elementos que vuelven más legítima la participación en actividades de socialización política?

10. ¿Cuáles son los mecanismos que vislumbras como más eficientes para conformar una protesta social?

11. Existe algo más que quieras agregar 